$$
\begin{aligned}
& \text { بهينهسازى بيان مسير بيوسنتز فلاونوئيد نارينجنين با استفاده از كشت سلولى ياروّيا } \\
& \text { لييوليتيكا }
\end{aligned}
$$

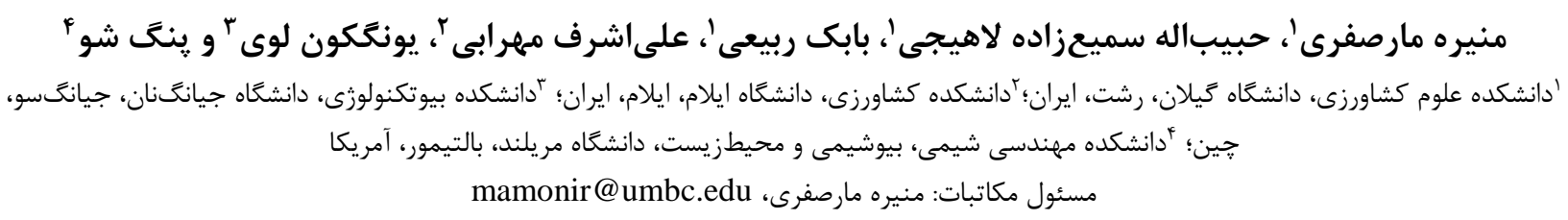

קكيده. امروزه استفاده از مخمر Yarrowia lipolytica به دليل برخوردارى از ظرفيت توليد بالا، كليكوزيله شدن در مقادير كم، برخوردارى از نشانكرهاى

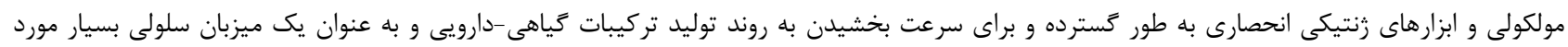

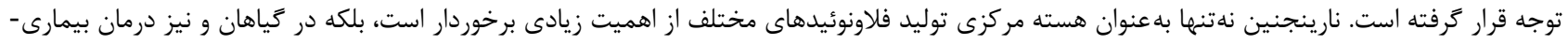

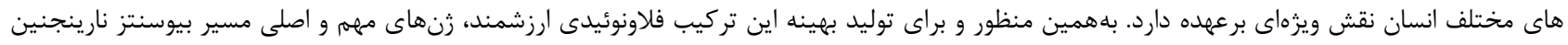

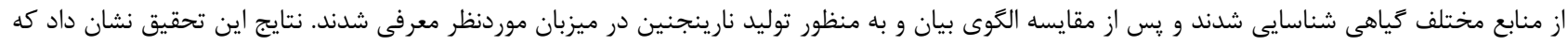

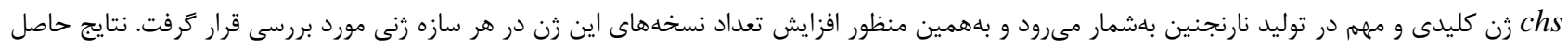

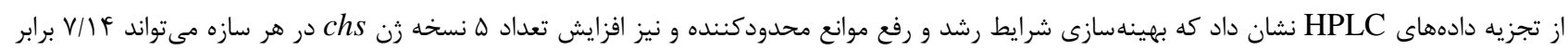

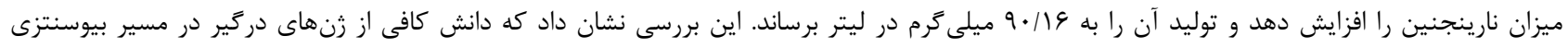

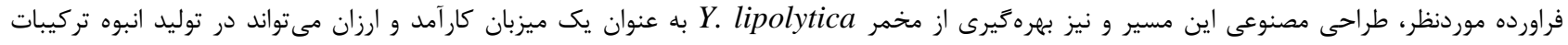
كياهى-دارويى نقش بهسزايى داشته باشد. وازههاى كليدى. تعداد نسخه زن، جريان متابوليسم، كروماتوكرافىمايع با كارايى بالا، ميزبان مخمر، مهندسى متابوليت

\title{
The optimization of Naringenin biosynthesis pathway using Yarrowia lipolytica cell culture
}

\section{Monireh Marsafari' ${ }^{1}$, Habibollah Samizadeh Lahiji', Babak Rabiei ${ }^{1}$, AliAshraf Mehrabi², Yongkun $\mathrm{Lv}^{3} \&$ Peng $\mathrm{Xu}^{4}$}

${ }^{1}$ Faculty of Agricultural Science, University of Guilan, Rasht, Iran; 2 Faculty of Agriculture, University of Ilam, Ilam, Iran; ${ }^{3}$ Faculty of Biotechnology, Jiangnan University, Jiangsu, China; ${ }^{4}$ Department of Chemical, Biochemical and Environmental Engineering, University of Maryland Baltimore County, Baltimore, USA Correspondent author: Monireh Marsafari, mamonir@umbc.edu

\begin{abstract}
Yarrowia lipolytica, as a good cell factory to speed up the production of plant pharmaceutical components, has been considered to be one of the most important and attractive micro-organisms in recent years, due to its high secretion capacity, limited glycosylation, large range of genetic markers and molecular tools. Naringenin, as a central core of flavonoids production, plays important roles both in plants and in the treatment of different types of human diseases. For this purpose, specific naringenin biosynthesis genes from different origins were selected and introduced after comparative expression profiling in $Y$. lipolytica. This research indicated that $c h$ s plays the main role in the production of naringenin, so the increase copy number of this gene in each construct was investigated. The HPLC results confirmed that the construct with 5 copy numbers of chs resulted in 7.14 fold increase of naringenin extracellular titer to $90.16 \mathrm{mg} / \mathrm{L}$ in shake flask cultures. The results reported in this study demonstrated that sufficient knowledge of genes involved in the specific biosynthesis pathway, synthetic gene pathway and using $Y$. lipolytica as a capable and cheap host could help bioengineers to produce significant amounts of pharmaceutical components.
\end{abstract}

Keywords. gene copy number, HPLC, metabolic engineering, metabolic flux, yeast host 
استخراج هستند. توليد شيميايى فلاونوئيدها نيز به دليل استفاده

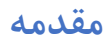
از حلالهاى شيميايى سمى و وجود خالش تغييرات شيميايى ضرورى مانند كليكوليزهشدن براى توليد تركيبات فعال توصيه

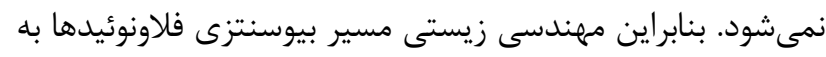

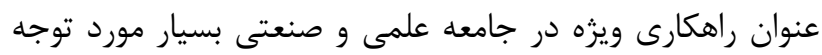
Atanasov et al., 2015; Chemler \& Koffas, ) قرار كرفت .2008; Fowler \& Koffas, 2009; Wang et al., 2011 كشت سوسيانسون سلول گياهى نيز به دليل نياز به كشت در مقياس وسيع، توليد مقدار انبوه تركيبات جانبى، تمايل سلولها

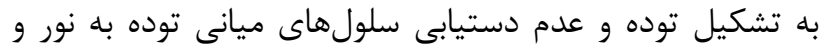

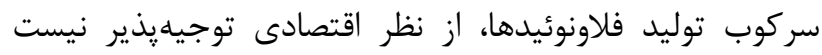

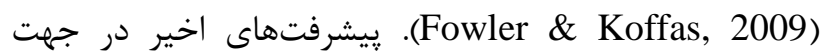
بهبود توليد فلاونوئيدها با استفاده از كارخانهاى سلولى

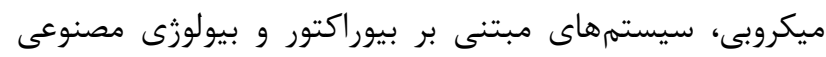

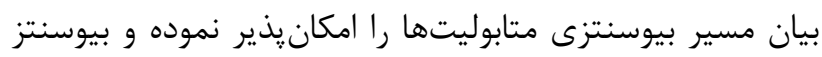
فراورده موردنظر را در زمان كوتاه و حجم انبوه امكانيذير مى دئ-

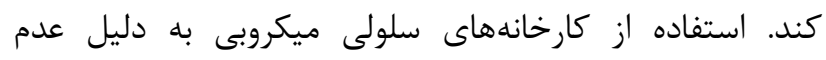

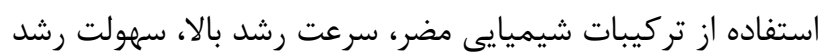
و تكثير و دسترسى به ابزارهاى زنتيكى متعدد؛ نسبت به به

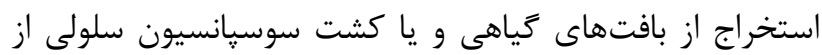
اهميت بالاترى برخوردار است (Trantas et al., 2015). تحمل در برابر pH يايين، ماهيت شديد هوازى، قابليت تطبيقيذيرى تجزيه سوبسترا با شرايط موجود، حضور مقدار زياد

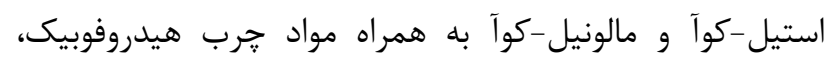
قابليت مصرف بخش زيادى از مواد كربنى خام به عنوان هنوان

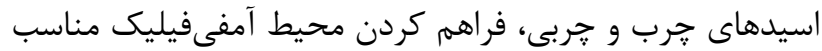

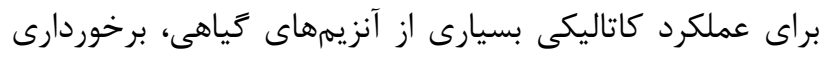
از غشاهاى ساختارى و محفظههاى سلولى جهت فراهي إنم كردن محيط هيدروفوبيك مناسب و نيز انتخاب استروئيدهاى موردنياز

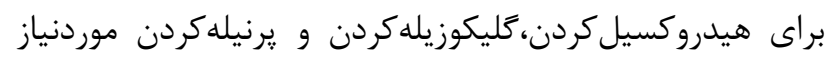

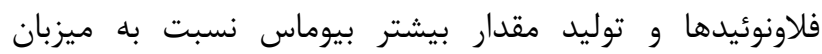

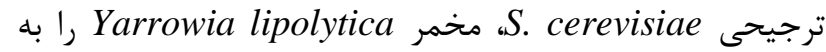
عنوان يك ميزبان قدرتمند براى توليد تركيبات طبيعى متنوع با سختار ييجيده تبديل كرده است (Lv et al., 2019b). تعادل جريان متابوليسمى و كاهش بار متابوليكى به واسطه بهبود

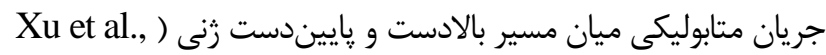
2013b)، رعايت حداقل تركيبات حدواسط براى حفظ زندهمانى

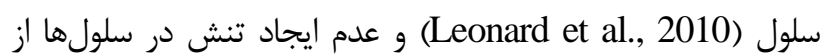
طريق بارگزارى بيشازحد از عوامل حياتى براى بهينهسازى توليد متابوليت در ريزسازوارهها هستند (Zelcbuch et al., 2013).

فلاونوئيدها يكى از مهمهرين زيركروههاى تركيبات يلىفنلى با

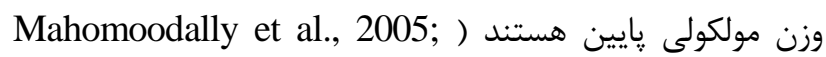
كه علاوه بر سازوكارهاى گوناكون در گياهان مانند (Pandy, 2007

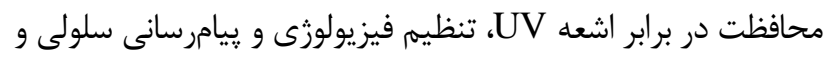
تنظيم گرددافشانى (Falcone Ferreyra et al., 2012)، براي درمان طيف وسيعى از بيمارىها ماند انواع سرطانها، جاقى، ديابت، بيمارىهاى قلبى عروقى و بيمارىهاى عصبى مورد هدف قران كرفتهاند (Panche et al., 2016). نارينجنين متعلق به زيمائ زيرشاخه

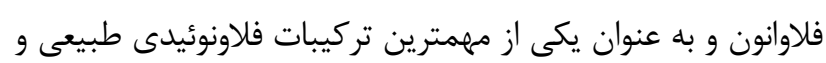

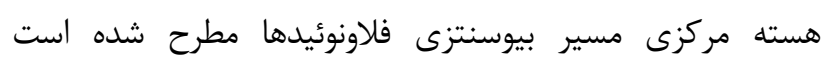
.(Winkel-Shirley, 2001) اسيد بیى-كوماريك توسط اسيد سيناميك و از طريق عمل

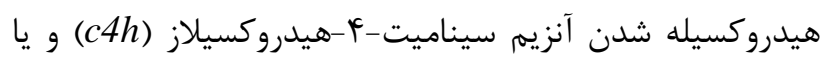

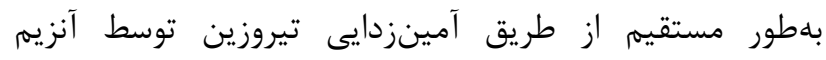

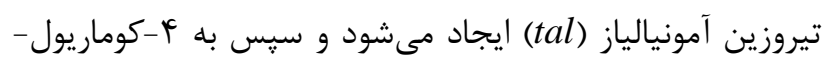

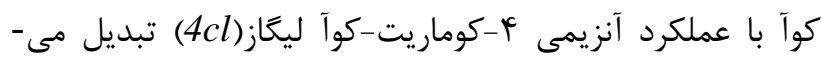

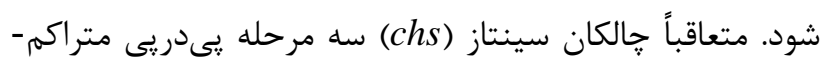

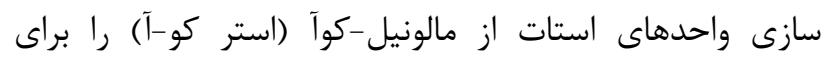

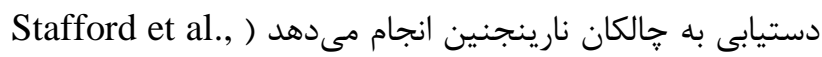
- 1974; Winkel, 2004

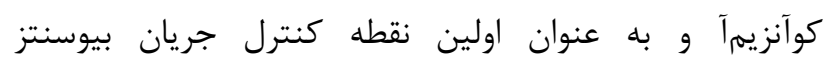

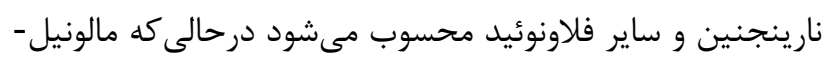

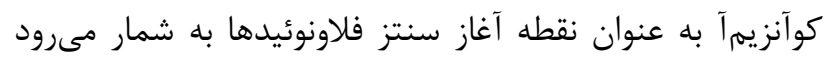

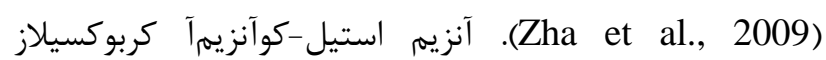

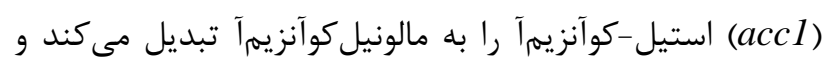

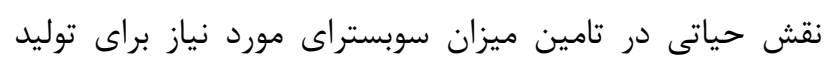

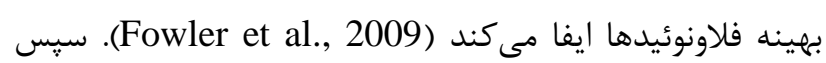

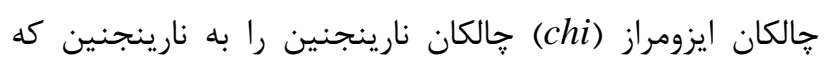

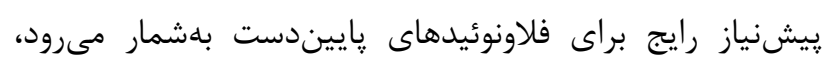

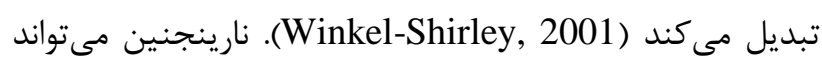

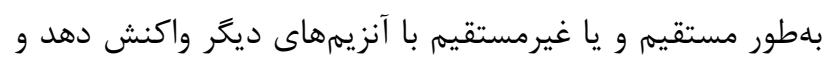

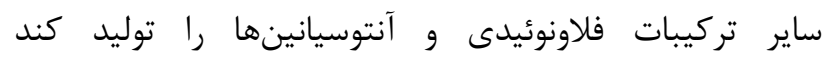
(Winkel-Shirley, 2002) توليد نارينجنين و به طوركلى فلاونوئيدها با استفاده از مواد

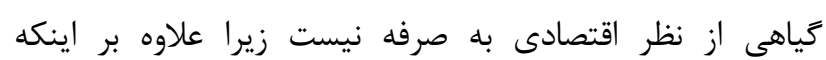

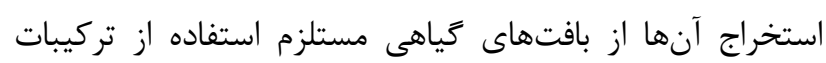

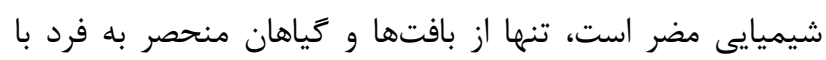

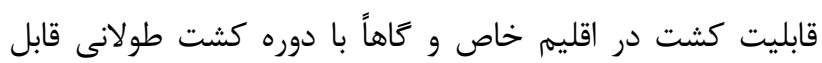




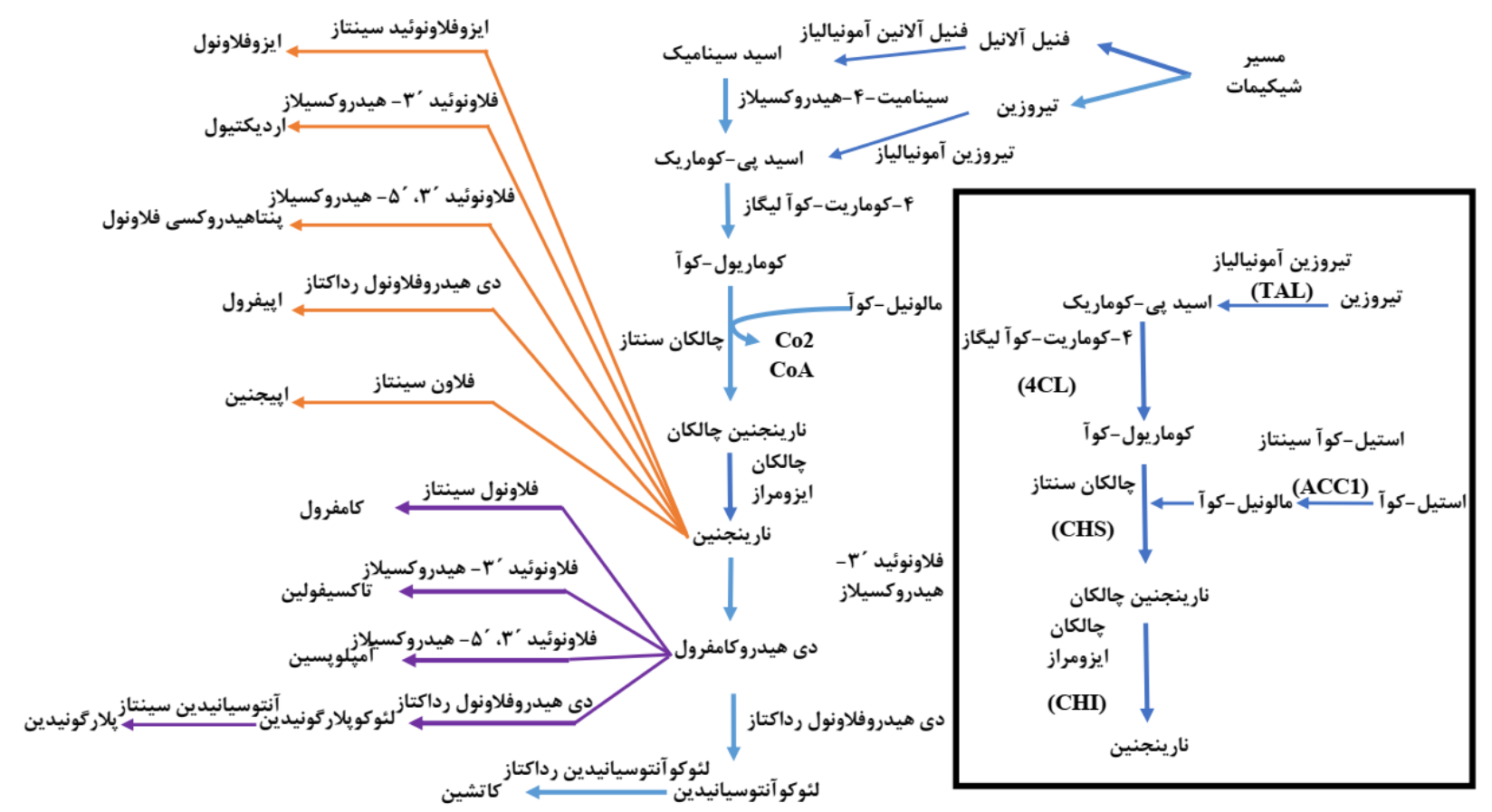

شكل ا- مسير عمومى بيوسنتز فلاونوئيدها. اين مسير با متابوليسم فنيل يرويانوئيد در بِلاستيد آغاز مىشود و با بكاركيرى يكسرى از آنزيمهاى متفاوت از شبكه

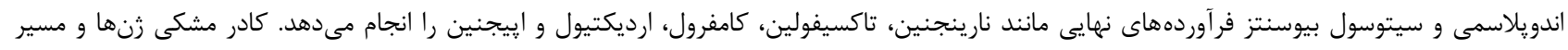

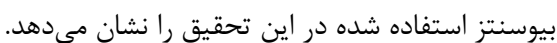

Fig. 1. The general biosynthesis pathway of flavonoids. This pathway begins with the metabolism of phenylpropanoid in the plastid and performs biosynthesis of end products such as naringenin, taxifoline, kaempferol, edicticol and epigenin using a series of different enzymes from the endoplasmic reticulum and cytosol. Genes and the biosynthetic pathway used in this study were shown in the black frame.

Yali به صورت ساختار مونوسيسترونيك و با استفاده از روش

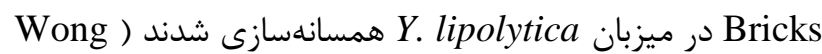

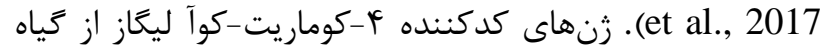
جعفرى (Petroselinum crispum; Pc4cl) و گوجهفرنگى (Solanum lycopersicum; Sl4cl) يتونيا (Petunia x hybrid; Phchs) و جو () (vulgare; Hvchs2

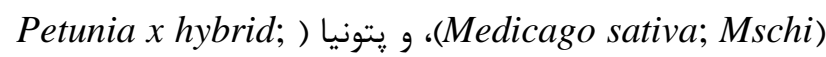
انتخاب شدند و براى شناسايى بهترين سازه حاوى (Phchi قدرتمندترين زنهاى يايه در تركيبهاى مختلف استفاده شدند.

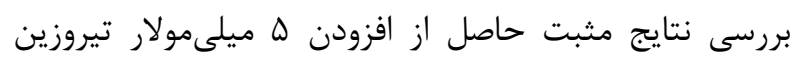
خارج سلولى به هر فلاسك حاوى مخمر تراريخت شده با سازه

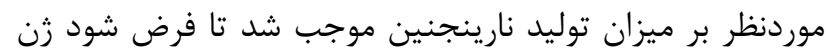

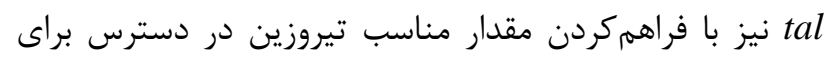
سويه مخمر مورد بررسى نقش قابل توجهى در توليد نارينجنين

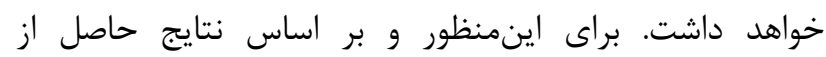
يثرهشهاى قبلى تاثير زن tal با منبع زنى
در اين يزوهش به منظور شناسايى كارامدترين زنهاى درگير در

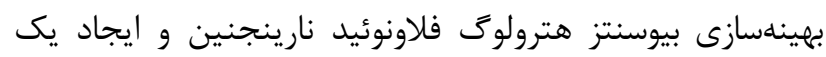

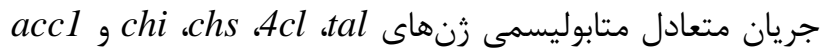
Y. از منابع زنى مختلف گرفته شد و قدرت بيان آنها در ميزبان lipolytica ميزبان مورد استفاده به عنوان يك كارخانه ميكروبى كارامد، با موردئ بهره گيرى از قند كلوكز به عنوان منبع قند، عدم توليد فراوردههاى اتانولى جانبى، روشهاى ساده مهرندسى زنتيكى و

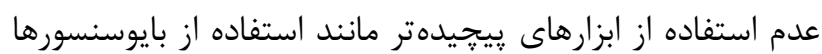
و يا كشت ميكروبى مخلوط مىتواند مقدار قابل توجهى فلاونوئيد نارينجنين توليد نمايد.

$$
\text { مواد و روشها }
$$

زن، يلاسميد و سويههاى مورد استفاده

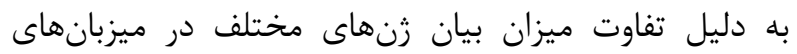

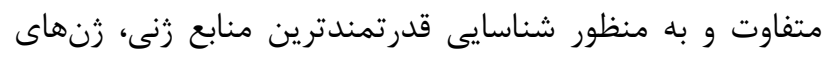

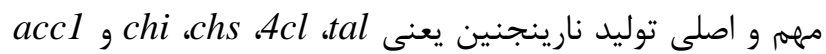


باكترى E E coli NEB $5 \alpha$ با ميكروليتر از مخلوط واكنش

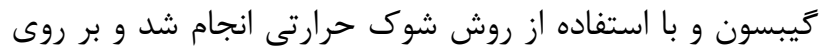

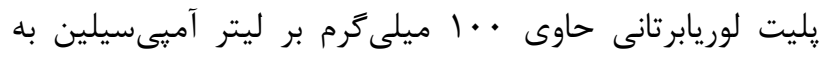

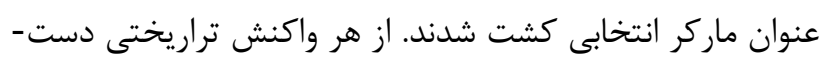

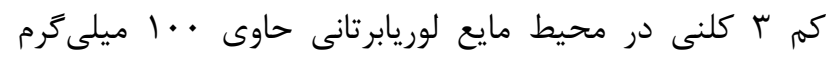

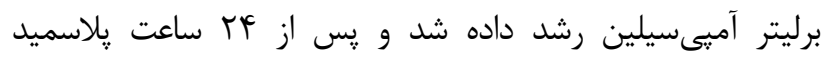

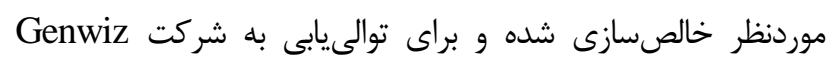

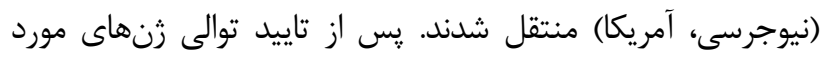
بررسى، با استفاده از روش سابكلونينگ و YaliBrick كه در ادامه به تهنه

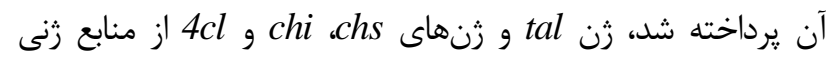
مختلف و هر يك با حفظ يروموتر، اينترون و ترميناتور مستقل (ساختار مونوسيسترونيك) در پلاسميد كيرنده وارد شدند.

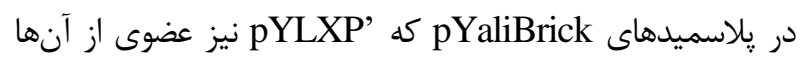
باشمار مىرود، جهار جايكاه آنزيمهاى برشى ايزوكدومر با انتهاى

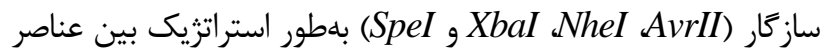

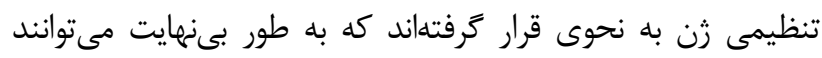

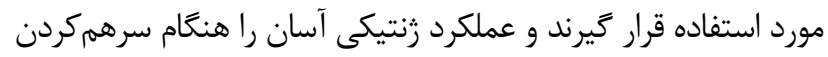
قطعات DNA به صورت ساختارهاى مونوسيسترونيك، خوشهزنى و يا خوشههاى رنى كاذب فراهم كنند باشد (Wong et al., 2017). در

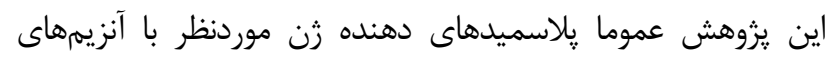

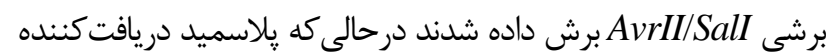

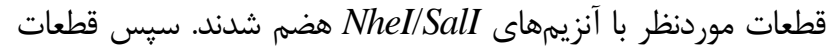

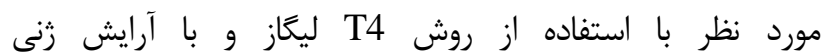

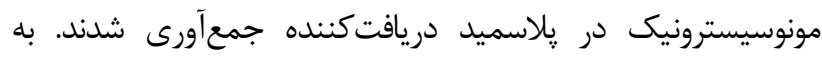

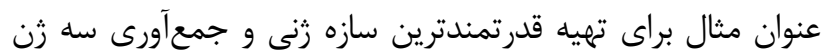
Pc4cl2 Mschi، Phchs كلونينَ براى ساير سازهها، ابتدا قطعه زن Mschi

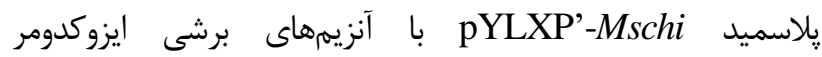
AvrII/Sall يلاسميد دريافت كننده NheI/SalI

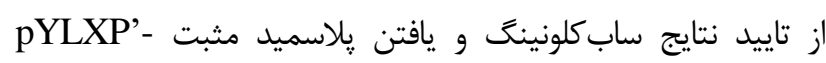
اين קيلاسميد نيز در محل آنزيمهاى برشى Phchs-Mschi به عنوان دريافت كننده براى قطعه رنى Pc4cl/Sall

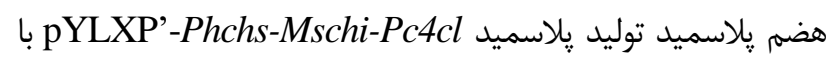

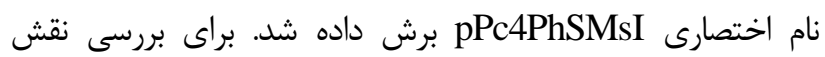

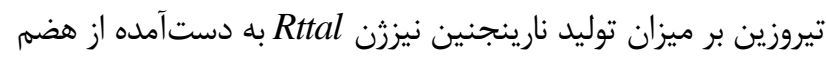

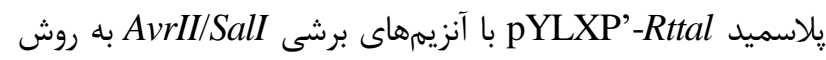

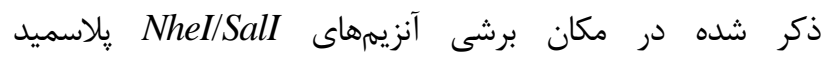
pPc4PhSMsI يلاسميدهاى مورد استفاده در اين تحقيق در جدول ب ذكر شدهاند.
Jiang et al., 2005; Lv et ) (Rttal به اختصار) toruloides al., 2019b; Santos et al., 2011; Zhang \& (Stephanopoulos, 2013; Zhang et al., 2017 توليد نارينجنين خارج سلولى مورد بررسى قرار كرفت.

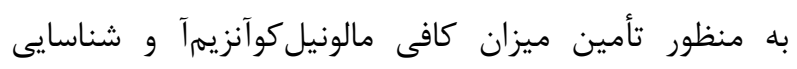

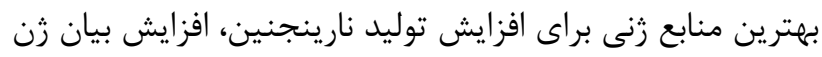

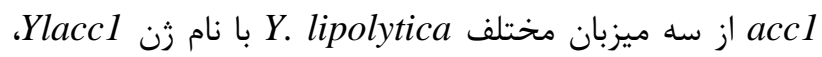
Corynebacterium glutamicum ATCC باكترى گرم مثبت 13032 با نام زن Cgacc1 و باكترى ترممنفى Escherichia coli MG1655 با نام زن Ecacc1 انجام شد. زن Ecacc1 جهار زن EcaccA، EcaccB

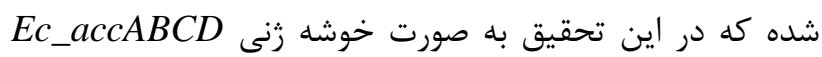

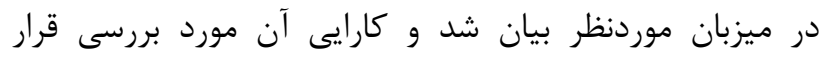

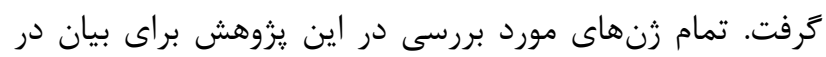

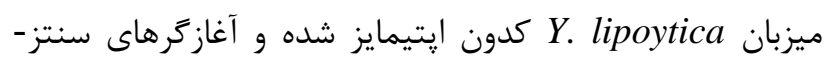

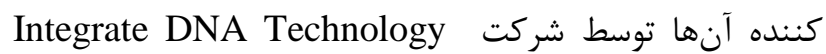
سنتز شدند. زنهاى مورد استفاده در اين (IDT), Iowa, USA يزوهش در جدول ا ارايه شدهاند. يلاسميد مورد استفاده در اين تحقيق، 'pYLXP بود كه قبلاً مطابق با استانداردهاى Yراحى و نكَهدارىشده بود (XuliBrick et al., 2016). باكترى Escherichia coli NEB $5 \alpha$ براى طراحى، تكثير و و

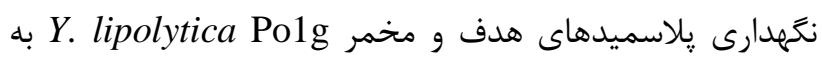
عنوان ميزبان براى توليد نارينجنين استفاده شد.

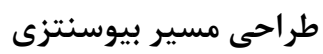

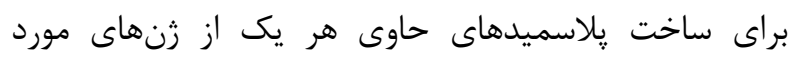

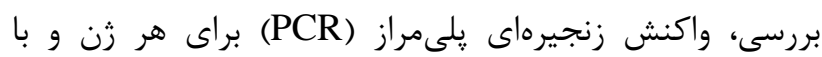

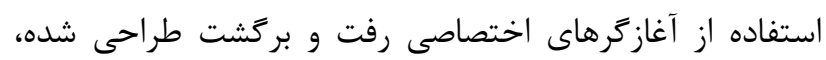

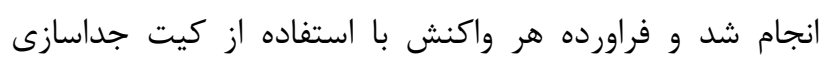
DNA clean\& concentrator-5 kit, ) DNA (Zymoresearch, USA pYLXP با استفاده از آنزيمهاى برشى SnaBI و

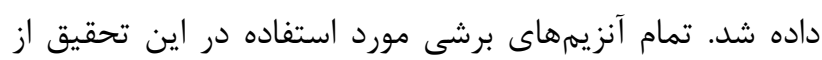

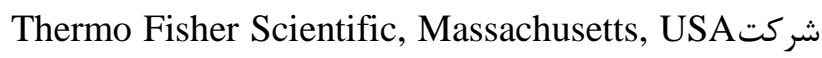
تهيه شدند. قطعات برشداده شده توسط الكتروفورز زل آكارز از

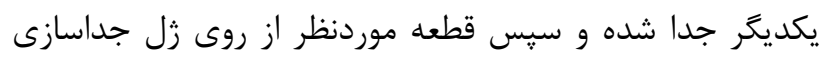
شدA gel ) DNA شوسط كيت بازيافت قطعات recovery kit, Zymoresearch, USA

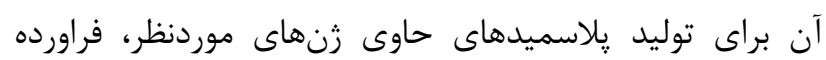

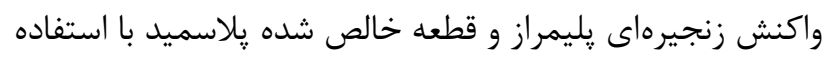

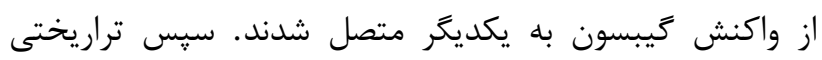


جدول ا- نام، منبع و شماره هر زن در קايعاه داده.

Table 1. Name, source and number of each gene in data source.

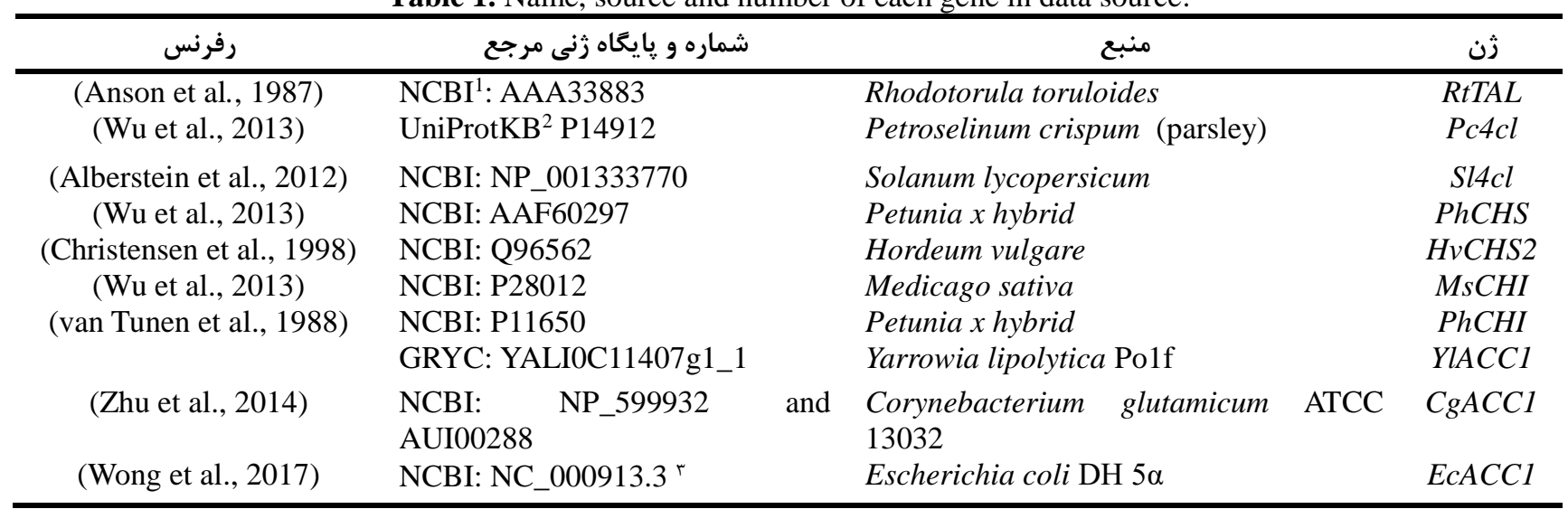

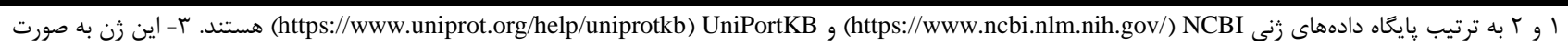

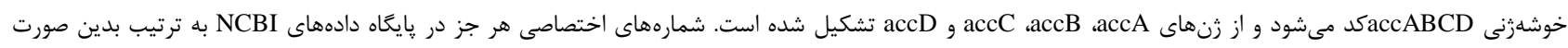

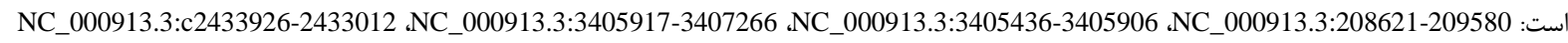
1 and 2 are NCBI (https://www.ncbi.nlm.nih.gov/) and UniPortKB (https://www.uniprot.org/help/uniprotkb) gene data bases, respectively. 3- This gene encoded by the accABCD operon and included acc $\mathrm{A}$, accB, accC and accD genes. The specific accession number of each gene is: NC_000913.3:208621-209580， NC_000913.3:3405436-3405906, NC_000913.3:3405917-3407266 and NC_000913.3:c2433926-2433012, respectively.

مخلوط شده و دست كم به مدت ها ثانيه و توسط ورتكس كاملا تركيب شدند. در اين مرحله 1-ه ميكروليتر از يلاسميد موردنظر

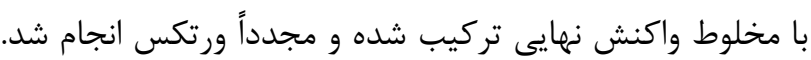

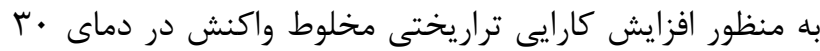

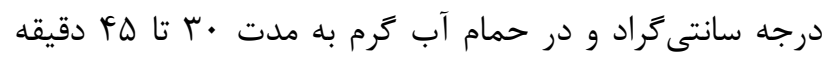
نَمهدارى شده و هر ده دقيقه يكبار به مدت • ا ثانيه ورتكس

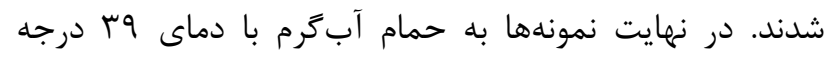

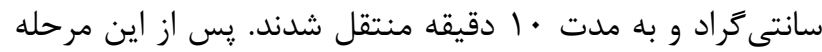
سلولهاى تراريخت شده بر روى : يليت محيط كشت كامل فاقد Complete Synthetic Media minus ) نشانگ لوسين كشت داده شدند و به مدت ب تا س روز (Leucine; CSM-Leu در دماى • r درجه سانتى گراد و در گرمخانه نتخهدارى شدند.

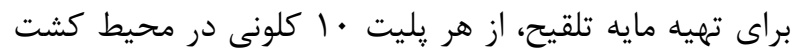
حقيقى مايع (CSM-Leu C/N=10) رشد داده شد و يس از

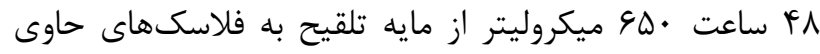

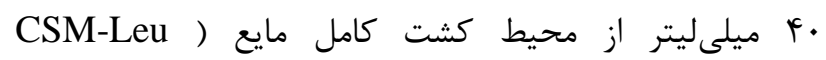

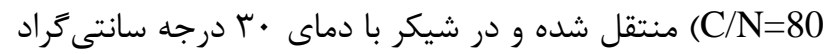

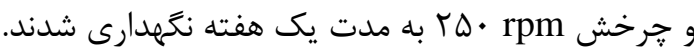

HPLC شناسايى و تعيين مقدار نارينجنين با استفاده از دستخًاه

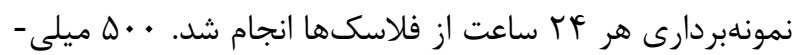
ليتر از محيط كشت كامل برداشت شد و به همان مقدار متانول با درجه خلوص HPLC به نمونهها اضافه شد. به منظور رهاسازى دمريط

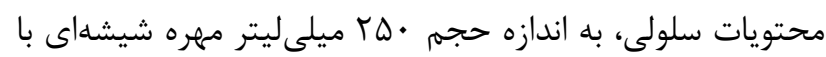
قطر ا ميلى متر به هر نمونه اضافه شد و به مدت يكى ساعت در
در مرحله بعد به منظور تعادل جريان متابوليسم، يافتن بهترين تركيب زنى و شناسايى زن بهبوددهنده ميزان توليد نارينجنين تعداد

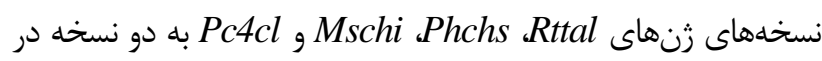
هر يلاسميد و بهصورت جداگانه براى هر زن در مكان برشى NheI/Sall pYT4SI4 pYT4SIT (جدول ץ). سيس براى بررسى اثرمتقابل دو نسخه از هر رن Rttal و Phchs Phchs

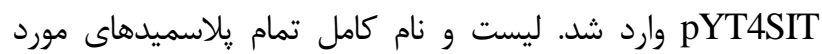
استفاده در اين يزوهش در جدول r ذكر شده است.

\section{تراريختى و غربال}

براى تراريختى Y. lipolytica از روش يايه ليتيوم استات با اندكى تغيير استفاده شد (Gietz \& Schiestl, 2007). در اين روش ابتدا مخمر YPD ب. lipolytica Po1g بر روى يليت 19-YY به مدت (Yeast Extract-Peptone-Dextrose) ساعت و در دماى • r درجه سانتى گراد رشد داده شد. به ازاى هر واكنش ه ميكروليتر از DNA تكرشتهاى اسيرم سالمون در دماى له درجه سانتى گراد و به مدت · • دقيقه حرارت داده شد

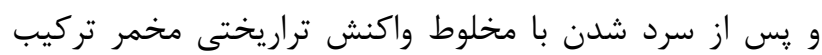

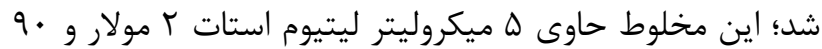

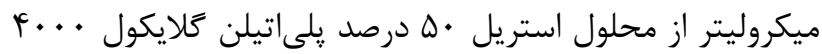

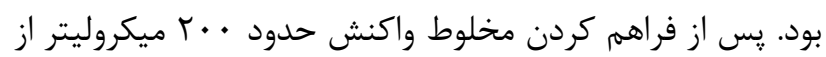
Y. lipolytica Po1g 


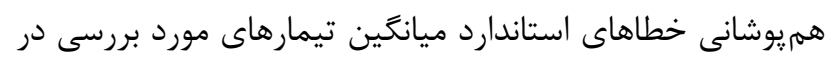

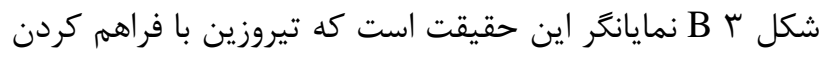
ميزان سوبستراى موردنياز براى سويه مخمر تراريخت با بهترين

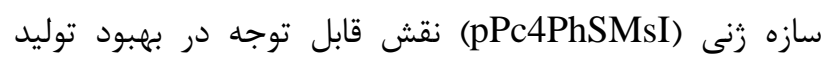

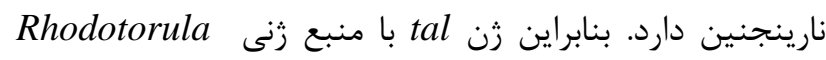
toruloides

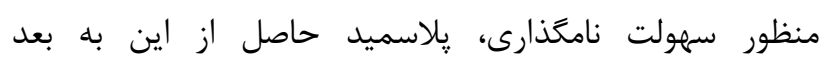
pYT4SI

تاثير تعداد نسخه هر ثن بر توليد نارينجنين

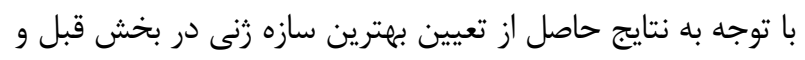

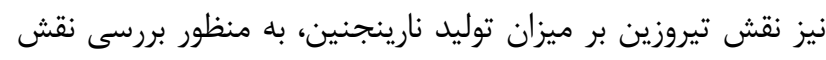

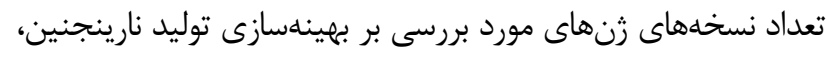

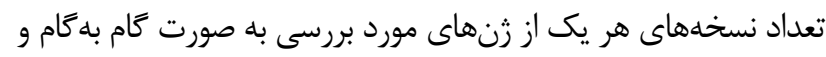

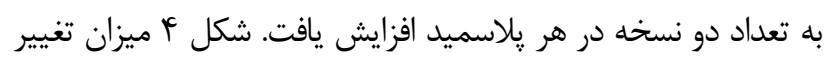

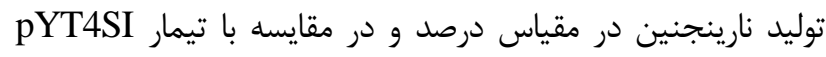

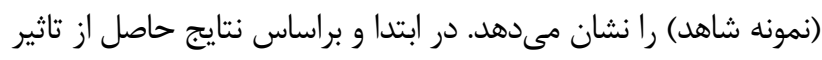

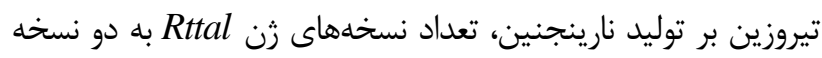

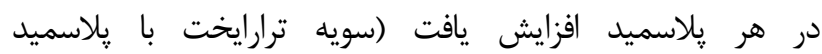
PYT4SIT

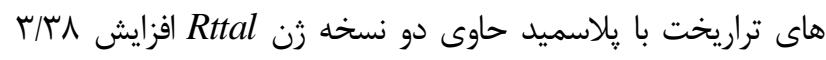

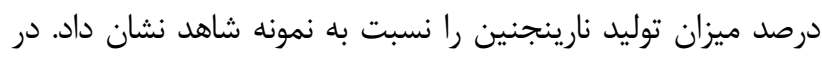

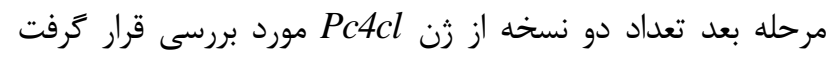

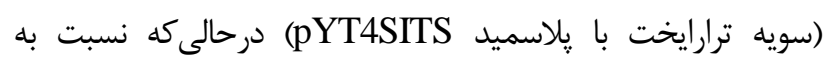

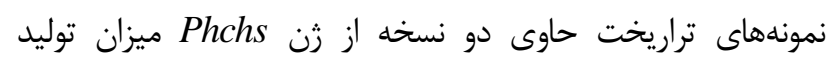

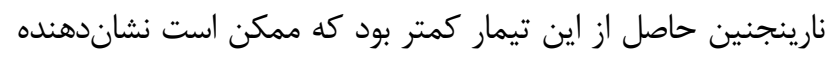

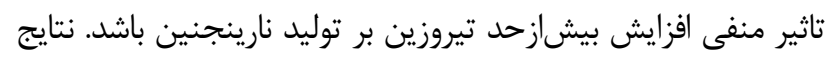

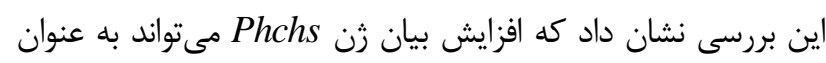

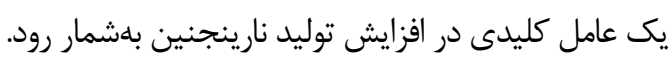

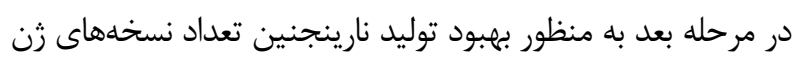
Phchs

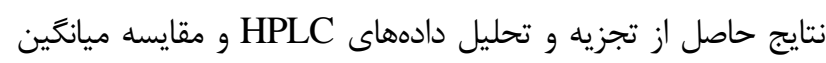
تيمارهاى مختلف به واسطه مقايسه هميوشانى خطاهاى استاندارد

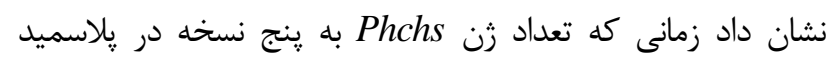

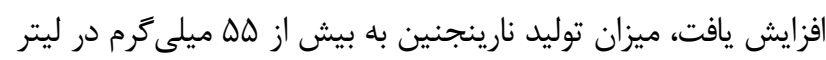

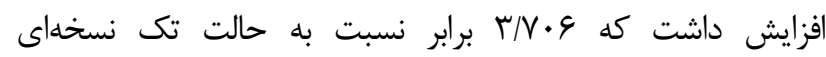

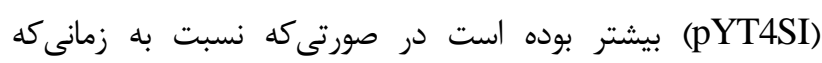

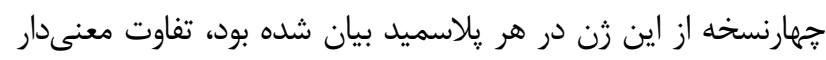

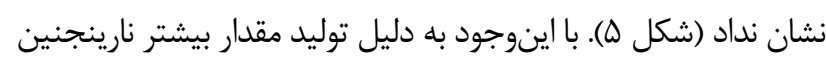

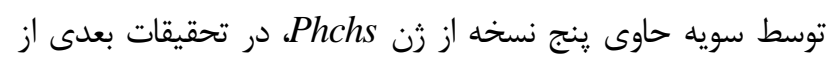

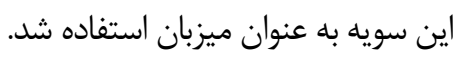

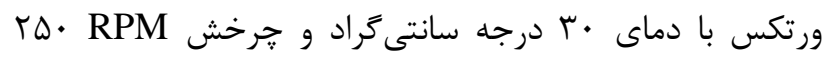

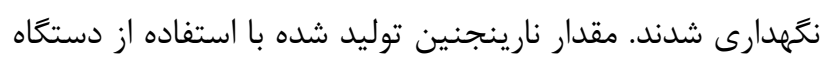
و به روش (Lv et al., 2019a 1220 ZORBAX Eclipse به منظور جداسازى نارينجنين از ستون Plus C18 (4.6 × 100 mm, 3.5 ㅆm, Agilent) تعيين آن نيز از مانيتور

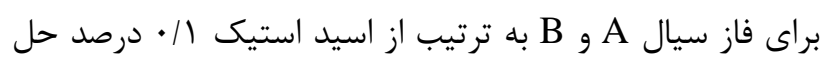

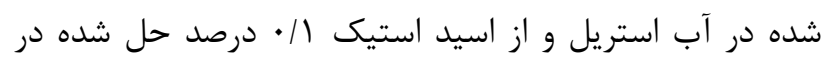

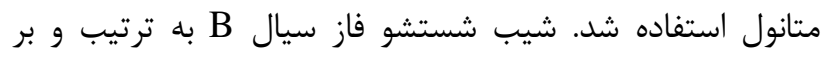

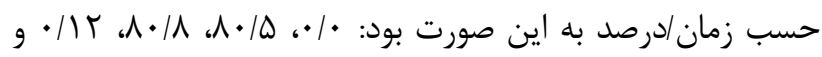

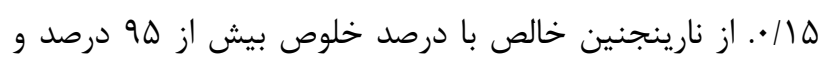

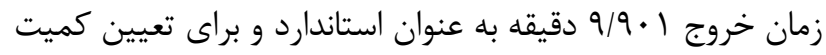

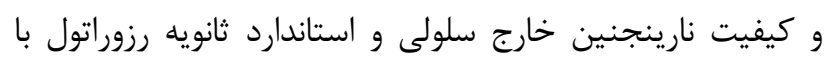

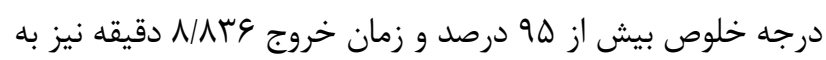
عنوان كنترل و جهت تشخيص دقيق نارينجنين از ساير تركيبات ممكن موجود در مخلوط واكنش استفاده شد. هر دو استاندارد

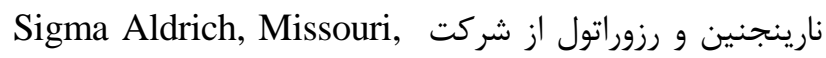

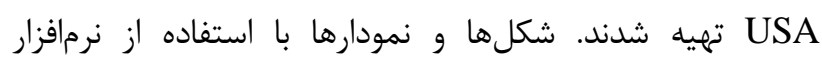
Adobe Illustrator CC, 2018 طراحى و ترسيم شدند.

نتايج تعيين بهترين منابع زنى جهت توليج

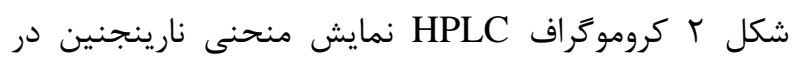

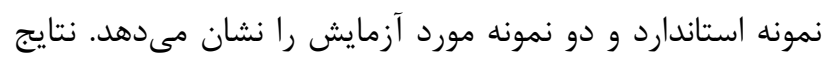

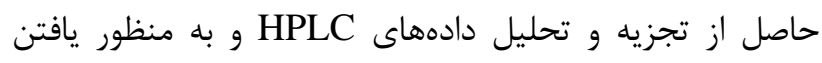

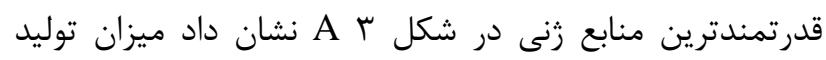

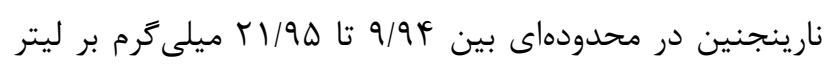

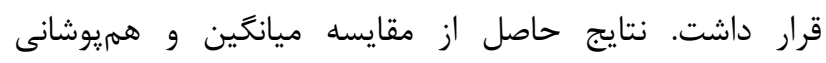

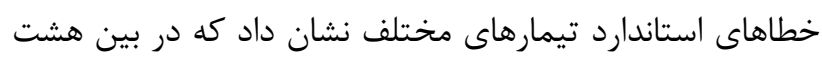

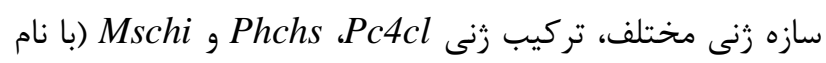

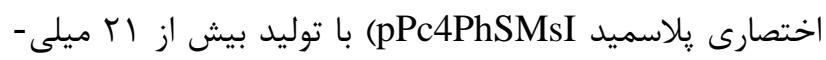

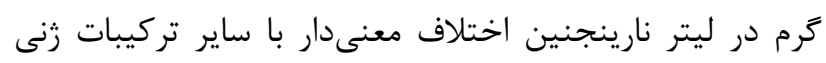

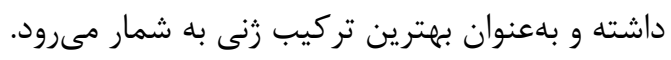

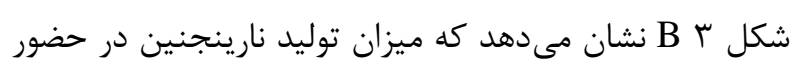

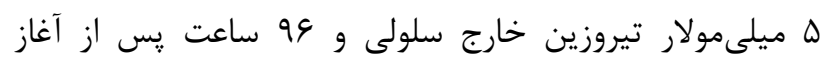

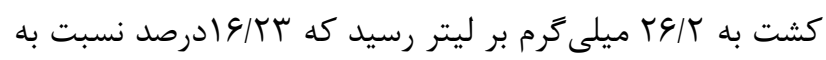

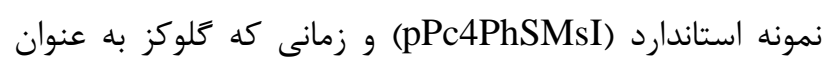
منبع اصلى سوبسترا بود، افزايش معنى دار نشان داد. عدم افزايش

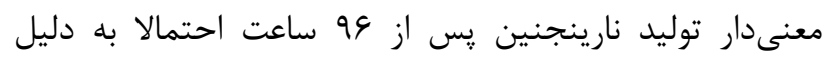

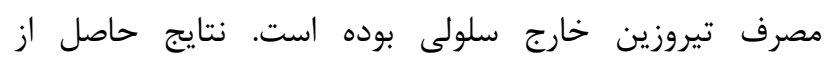


جدول r- فهرست پِلاسميدهاى مورد استفاده در اين يزوهش.

Table 2. List of plasmids used in this study.

\begin{tabular}{|c|c|c|}
\hline 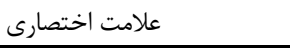 & نام كامل هر يلاسميد & 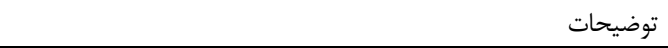 \\
\hline pYLXP & & يلاسميد مورد استفاده براى تمام مر احل همسانه سازى \\
\hline $\mathrm{pRtT}$ & pYLXP'-Rttal & يلاسميد pYLXP دربردارنده زن Rttal \\
\hline pPc4 & pYLXP'-Pc4cl & يلاسميد pYLXP دربردارنده زن Pc4cl \\
\hline pSL4 & pYLXP'-Sl4cl & يلاسميد pYLXP دربردارنده زن Sl4cl \\
\hline $\mathrm{pPhS}$ & pYLXP'-Phchs & يلاسميد pYLXP دربردارنده زن Phchs \\
\hline pHvS2 & pYLXP'-Hvchs2 & يلاسميد pYLXP دربردارنده زن Hvchs2 \\
\hline pMsI & pYLXP'-Mschi & يلاسميد pYLXP دربردارنده زن Mschi \\
\hline $\mathrm{pPhI}$ & pYLXP'-Phchi & يلاسميد pYLXP دربردارنده زن Phchi \\
\hline pYlA1 & pYLXP'-Ylaccl & يلاسميد pYLXP دربردارنده زن Ylacc1 \\
\hline pCgA1 & pYLXP'-Cgaccl & يلاسميد pYLXP دربردارنده زن Cgacc1 \\
\hline $\mathrm{pEcA} 1 \mathrm{~A}$ & pYLXP`-EcacclA & يلاسميد pYLXP دربردارنده زن Ecacc1A \\
\hline $\mathrm{pEcA1B}$ & pYLXP'-EcacclB & يلاسميد pYLXP دربردارنده زن Ecacc1B \\
\hline $\mathrm{pEcA} 1 \mathrm{C}$ & pYLXP`-EcacclC & يلاسميد pYLXP دربردارنده زن Ecacc1C \\
\hline $\mathrm{pEcA} 1 \mathrm{D}$ & pYLXP'-Ecacc1D & يلاسميد pYLXP دربردارنده زن Ecacc1D \\
\hline $\mathrm{pEcA} 1 \mathrm{ABCD}$ & pYLXP`-Ecacc $1 A B C D$ & يلاسميد pYLXP دربردارنده زن كامل EcacclABCD \\
\hline pPc4PhSMsI & pYLXP'-Pc4cl-Phchs-Mschi & يلاسميد pYLXP دربردارنده زنهاى Pschi Phchs، Pc4cl \\
\hline pPc4PhSPhI & pYLXP'-Pc4cl-Phchs-Phchi & يلاسميد pYLXP دربردارنده زنهاى Phchi Phchs، Pc4cl \\
\hline pPc4HvSMsI & pYLXP'-Pc4cl-Hvchs-Mschi & يلاسميد pYLXP دربردارنده زنهاى Pc4ch و Hvchs Pcli \\
\hline pPc4HvSPhI & pYLXP'-Pc4cl-Hvchs-Phchi & يلاسميد pYLXP دربردارنده زنهاى Phchi, Hvchs Pc4cl \\
\hline pS14PhSMsI & pYLXP'-Sl4cl-Phchs-Mschi & يلاسميد pYLXP دربردارنده زنهاى Mschi Phchs، Sl4cl \\
\hline pS14PhSPhI & pYLXP'-Sl4cl-Phchs-Phchi & يلاسميد pYLXP دربردارنده زنهاى Phchi, Phchs، Sl4cl \\
\hline pS14HvSMsI & pYLXP'-Sl4cl-Hvchs-Mschi & يلاسميد pYLXP دربردارنده زنهاى Mschi Hvchs، Sl4cl \\
\hline pS14HvSPhI & pYLXP`-Sl4cl-Hvchs-Phchi & يلاسميد pYLXP دربردارنده رنهاى Phchi Hvchs، Sl4cl \\
\hline pYT4SI & pYLXP`-Rttal-Pc4cl-Phchs-Mschi & يلاسميد pYLXP دربردارنده رنهاى Rttal، Pc4cl، Phchs و \\
\hline & & Mschi \\
\hline pYT4SIT & pYLXP'-Rttal-Pc4cl-Phchs-Mschi-Rttal & يلاسميد pYT4SI در بردارنده دونسخه از زن Rttal \\
\hline pYT4SI4 & pYLXP`-Rttal-Pc4cl-Phchs-Mschi-Pc4cl & يلاسميد pYT4SI در بردارنده دونسخه از زن Pc4cl \\
\hline pYT4SIS & pYLXP'-Rttal-Pc4cl-Phchs-Mschi-Phchs & يلاسميد pYT4SI در بردارنده دونسخه از زن Phchs \\
\hline pYT4SII & pYLXP'-Rttal-Pc4cl-Phchs-Mschi-Mschi & يلاسميد pYT4SI در بردارنده دونسخه از زن Mschi \\
\hline pYT4SI4S & $\begin{array}{l}\text { pYLXP'-Rttal-Pc4cl-Phchs-Mschi-Pc4cl- } \\
\text { Phchs }\end{array}$ & يلاسميد pYT4SI در بردارنده دونسخه از هر زن Pc4cl و Phchs \\
\hline pYT4S $\mathrm{S}_{\mathrm{x} 2 \mathrm{I}}$ & pYLXP`-Rttal-Pc4cl-Phchs $s_{x 2}-M s c h i$ & يلاسميد pYT4SI در بردارنده دو نسخه از زن Phchs \\
\hline pYT4S $\mathrm{S}_{33} \mathrm{I}$ & pYLXP`-Rttal-Pc4cl-Phchs $x_{x 3}-M s c h i$ & يلاسميد pYT4SI در بردارنده سه نسخه از زن Phchs \\
\hline pYT4S $\mathrm{S}_{\mathrm{x}} \mathrm{I}$ & pYLXP'-Rttal-Pc4cl-Phchs $s_{x 4}-M s c h I$ & يلاسميد pYT4SI در بردارنده جهار نسخه از ثن Phchs \\
\hline pYT4S $x_{55} \mathrm{I}$ & pYLXP`-Rttal-Pc4cl-Phchs $s_{x 5}-M s c h i$ & يلاسميد pYT4SI در بردارنده ينج نسخه از ثن Phchs \\
\hline pYT4S $\times 5 \mathrm{I}-\mathrm{Cgaccl}$ & $\begin{array}{l}\text { pYLXP'-Rttal-Pc4cl-Phchs } x_{x}-\text { Mschi- } \\
\text { Cgaccl }\end{array}$ & يلاسميد pYT4S \\
\hline pYT4S ${ }_{\times 5} \mathrm{I}-E c a c c 1 A B C D$ & $\begin{array}{l}\text { pYLXP'-Rttal-Pc4cl-Phchs } s_{x 5}-M s c h i- \\
\text { EcacclABCD }\end{array}$ & يلاسميد pYT4S در بردارنده زن EcacclABCD \\
\hline pYT4S $\mathrm{S}_{\mathrm{x} 5} \mathrm{I}-\mathrm{Ylaccl}$ & pYLXP'-Rttal-Pc4cl-Phchs $s_{x 5}-$ Mschi-Ylacc1 & يلاسميد pYT4S در بردارنده زن Ylacc1 \\
\hline
\end{tabular}




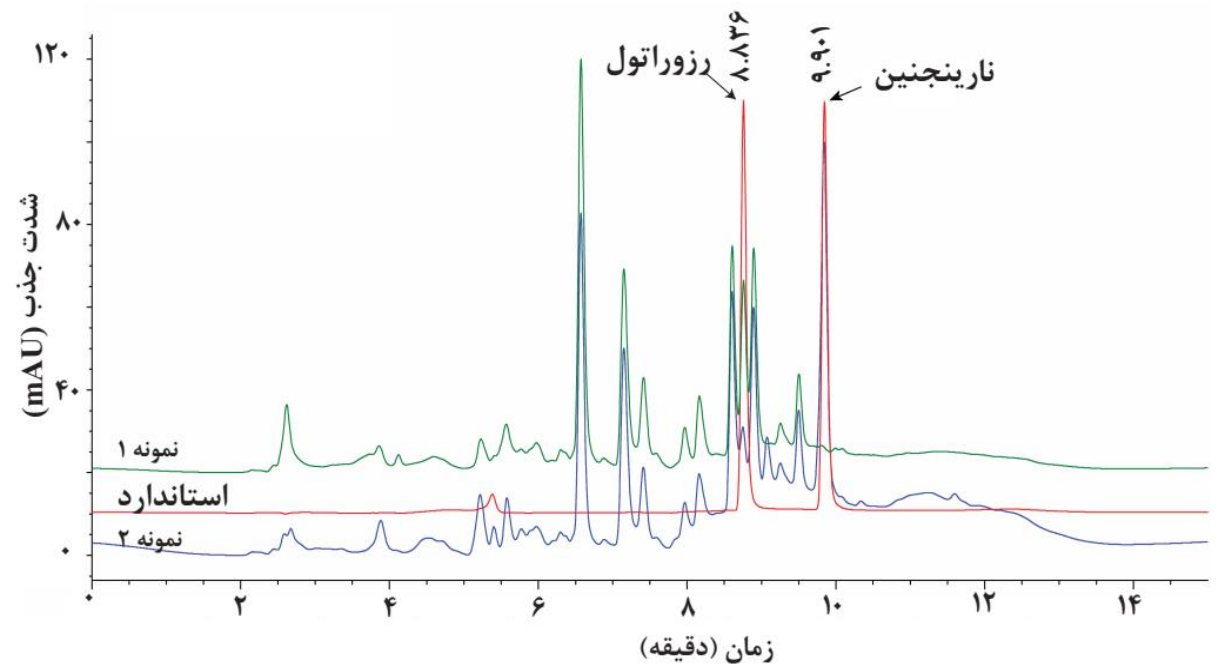

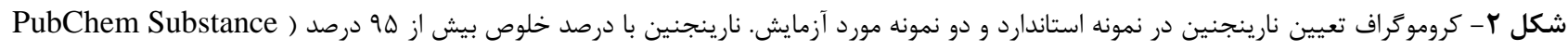

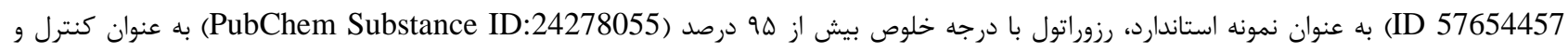

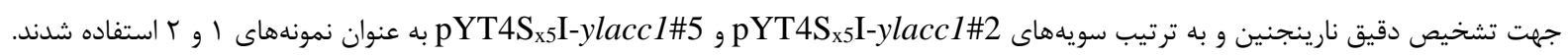

Fig. 2. Naringin chromatograph in standard and two tested samples. Naringin with a purity of more than $95 \%$ (PubChem Substance ID 57654457) as the standard sample, Resveratol with a purity of more than 95\% (PubChem Substance ID:24278055) as a control and for accurate diagnosis of Naringenin and pYT4S $\mathrm{x}_{55} \mathrm{I}-\mathrm{ylacc}$ l\#2 and $\mathrm{pYT} 4 \mathrm{~S}_{\mathrm{x} 5} \mathrm{I}-$ ylaccl\#5 strains were used as samples 1 and 2, respectively.

A

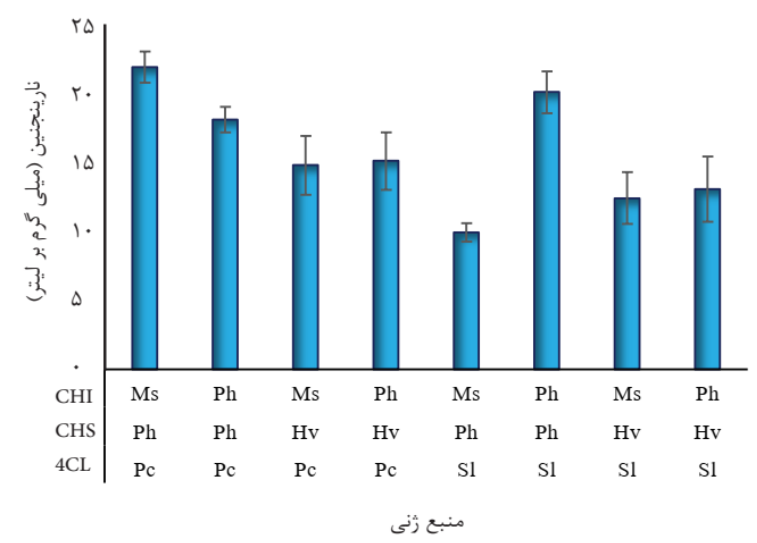

B

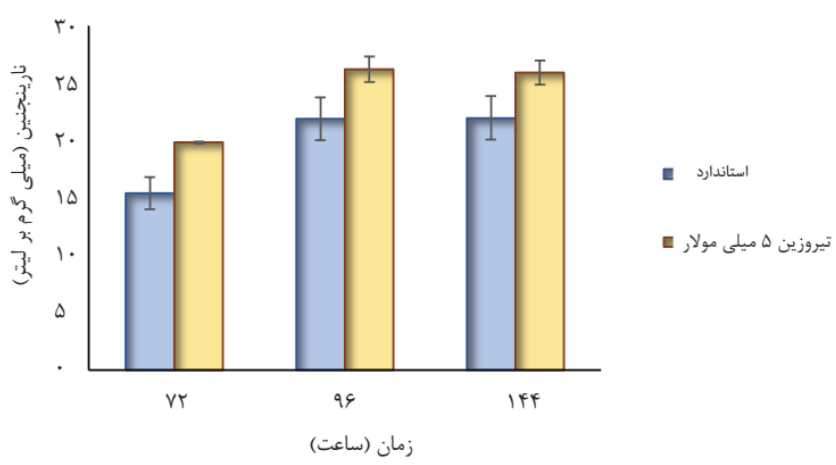

شكل r. نمايش تركيب رنى و نقش تيروزين بر توليد نارينجنين در ميزبان A .Y. lipolytica. تاثير منبع رنى بر قدرت بيان سه زن بيوسنتزى پايه به منظور

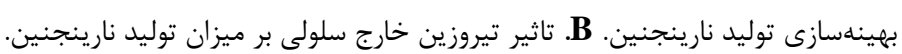

Fig. 3. Gene composition and the role of tyrosine on the production of naringenin in Y. lipolytica host. A. The effect of gene source on the expression of three basic biosynthetic genes to optimize naringenin production. $\mathrm{B}$. The effect of extracellular tyrosine on naringenin titer.

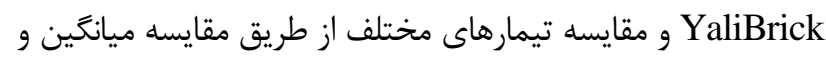

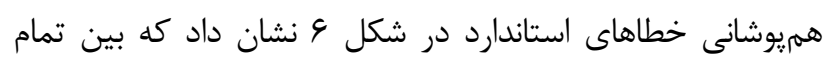

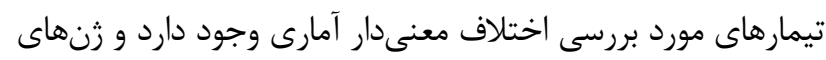

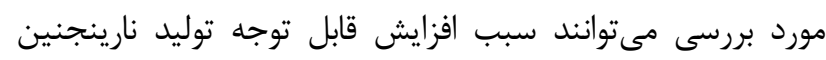

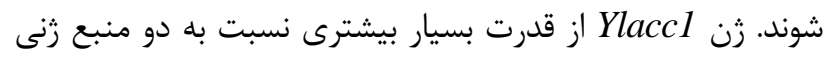

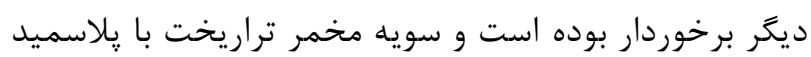

تاثير منابع استيل-كوآنزيمآ و مالونيلكوآنزيمآ بر ميزان توليد نارينجنين نتايج حاصل از تجزيه و تحليل دادههاى HPLC برائ براى بررسى

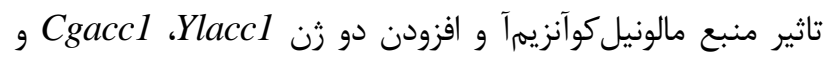

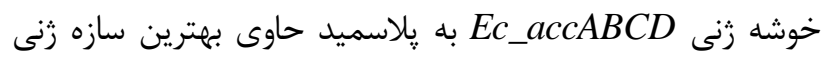

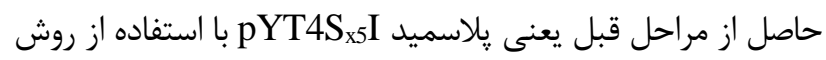


Zالت تك كشت مخمر 1 برابر افزايش داشت ( Zhang et al.,

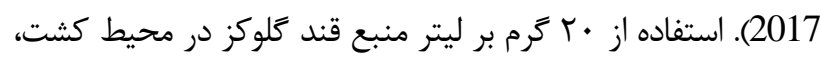

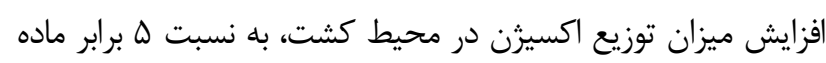

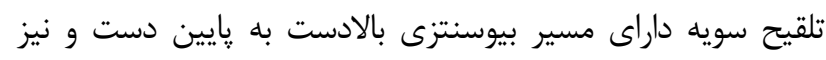

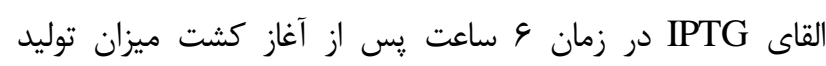

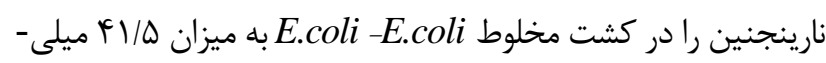

كرم بر ليتر رساند (Ganesan et al., 2017). تعادل مسير بيوسنتزى، يعنى هماهنگى ميزان تجمع و مصرف رئن

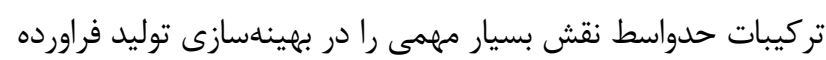

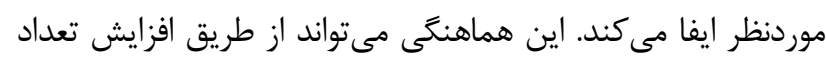

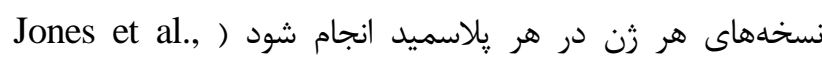

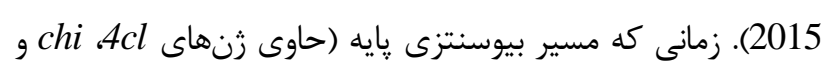
chs

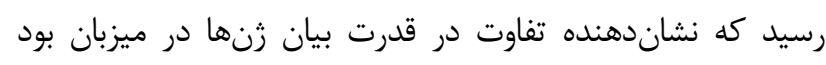

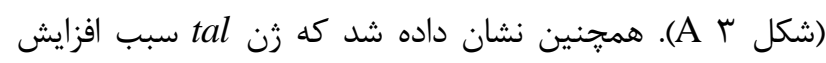

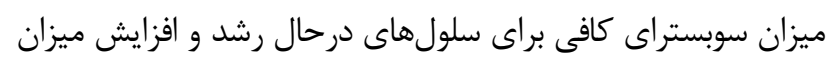

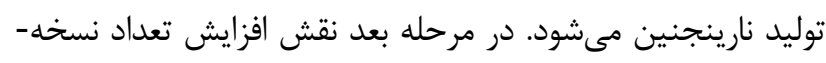

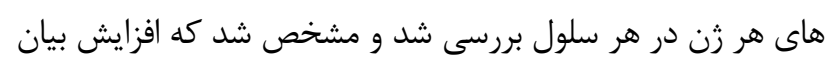

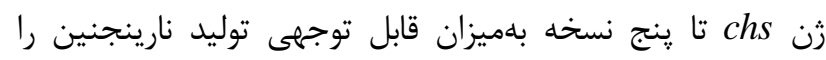

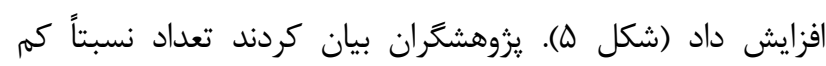

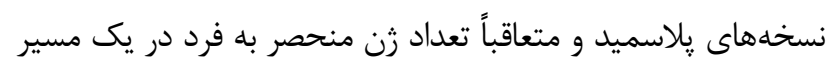

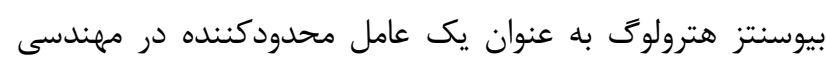

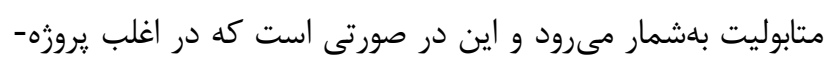

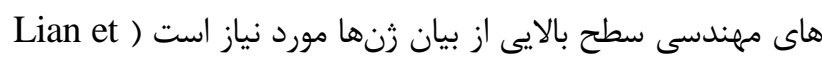
E. coli al., 2018

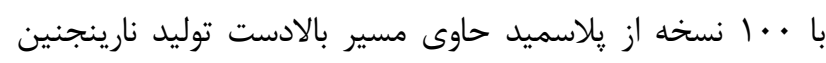

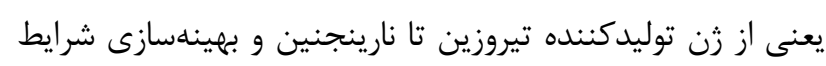

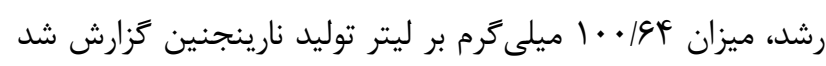

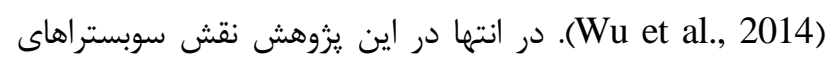

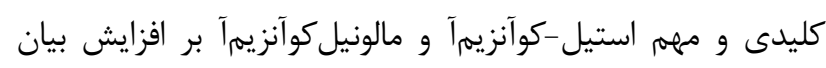

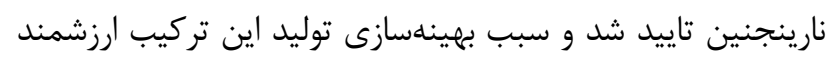

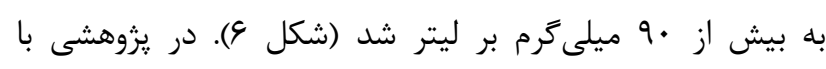

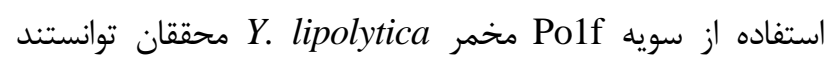

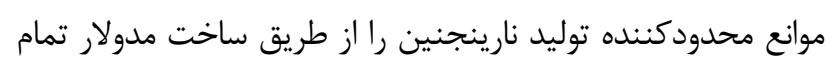

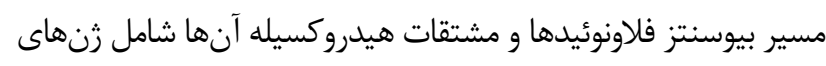

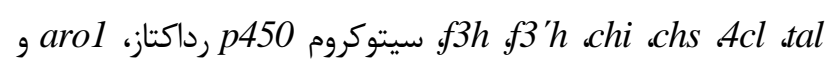
acc1

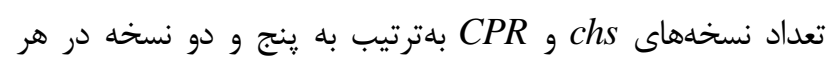

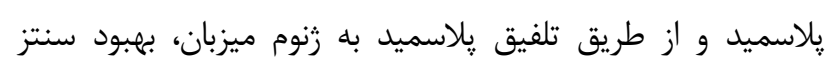

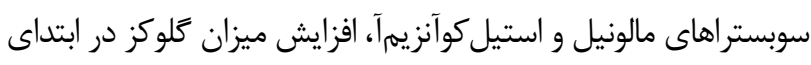

pYT4Sx5I-Ylacc1 ميلى

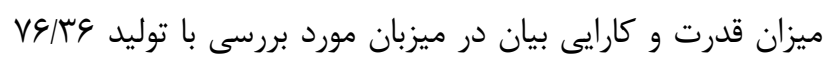

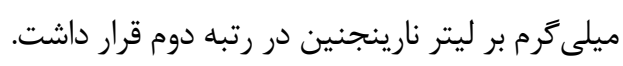

\section{بحث و نتيجه كيرى}

به دليل نترانىهايى كه درمورد ايمنى صنايع غذايى و محيط

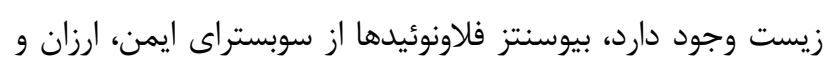

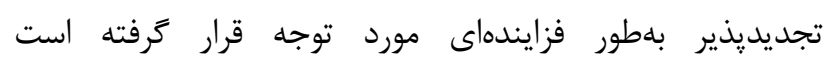
(Koopman et al., 2012; Santos et al., 2011) عنوان هسته مركزى توليد فلاونوئيدها، يك تركيب طبيعى بسيار

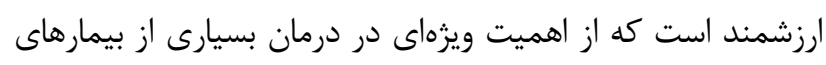

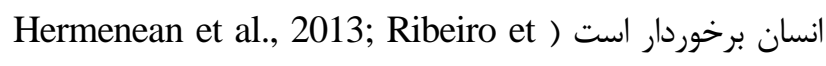
al., 2008; Xu et al., 2013a

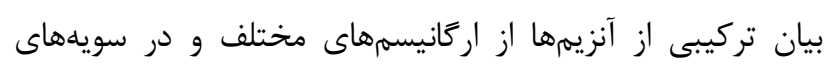

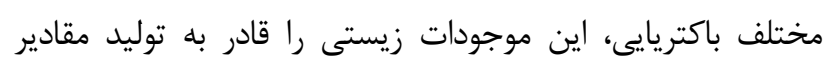
قابلتوجهى نارينجنين كرده است. مخمر

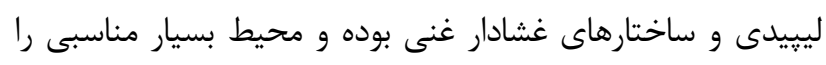

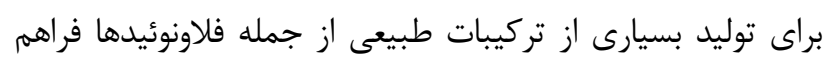

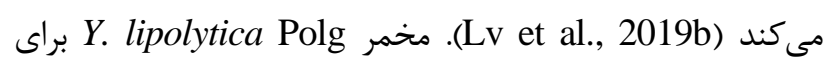
توليد نارينجنين و براى اولين بار در اين بروهش مورد مورد استفاده قرار

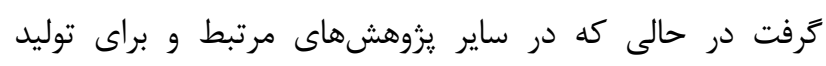

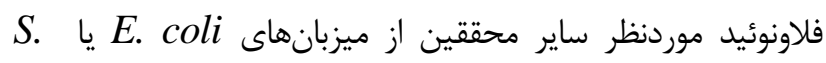
cerevisiae

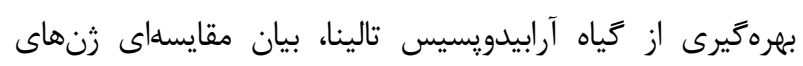

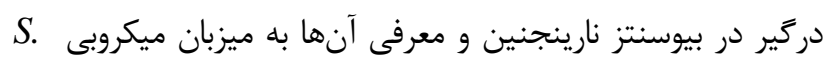
-cerevisiae

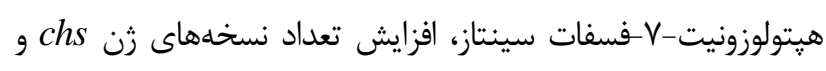

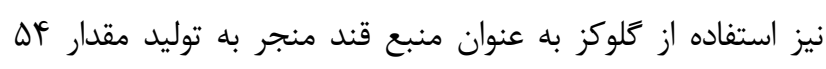
ميلى

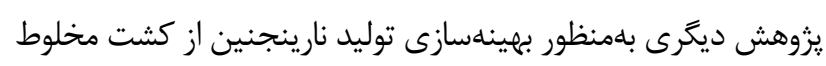

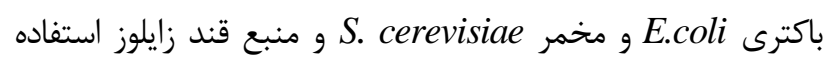

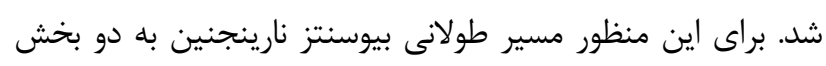
تفكيك شد و هر بخش به يكى از ميزبانهاى مورد استفاده وارد شد.

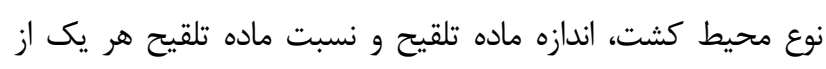

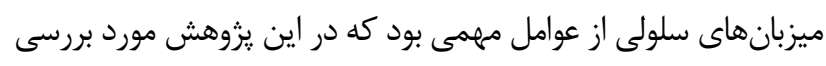

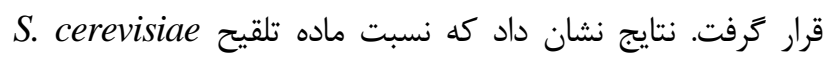

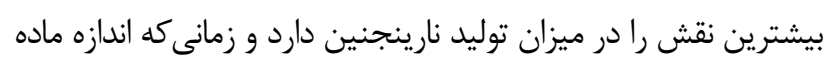

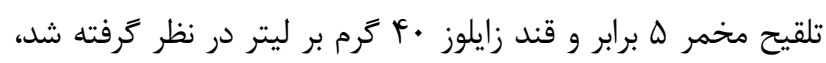

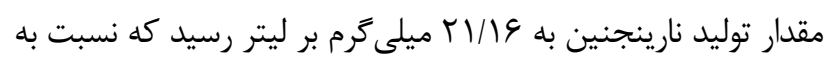




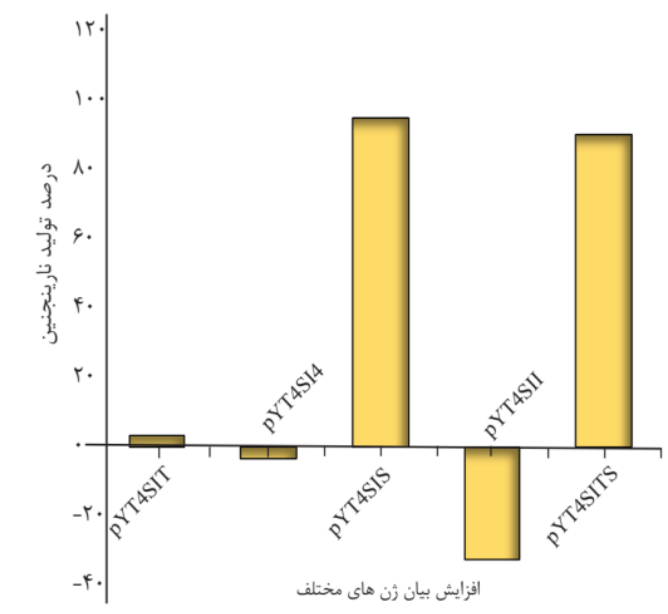

شكل F- تاثير تعداد نسخهاى هر رن بر ميزان توليد نارينجنين.

Fig. 4. The effect of gene copy number on naringenin titer.

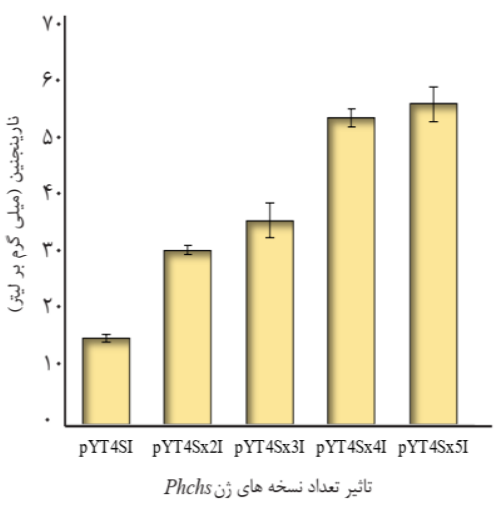

شكل ه- تاثير افزايش تعداد نسخههاى زن Phchs تا ينج نسخه در هر پيلاسميد بر ميزان توليد نارينجنين.

Fig. 5. The effect of Phchs gene copy number (up to five copies) in each plasmid on naringenin titer.

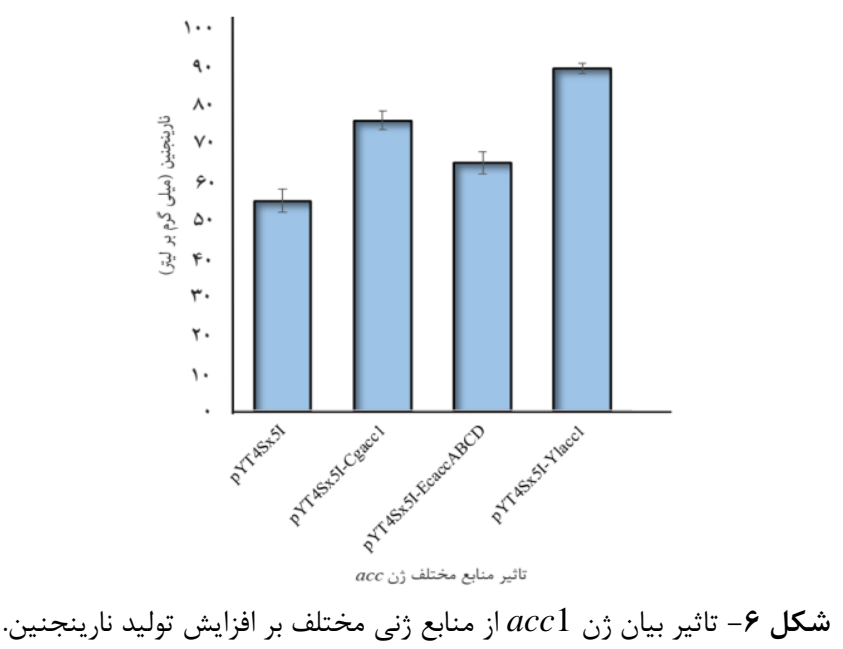

Fig. 6. The effect of acc 1 gene expression on the improvement of naringenin titer. 


\section{References}

Alberstein, M., Eisenstein, M. \& Abeliovich, H. 2012. Removing allosteric feedback inhibition of tomato 4coumarate:CoA ligase by directed evolution. Plant $\mathrm{J}$. 69: 57-69.

Anson, J.G., Gilbert, H.J., Oram, J.D. \& Minton, N.P. 1987. Complete nucleotide sequence of the Rhodosporidium toruloides gene coding for phenylalanine ammonia-lyase. Gene 58: 189-199.

Atanasov, A.G., Waltenberger, B., Pferschy-Wenzig, E.M., Linder, T., Wawrosch, C., Uhrin, P., Temml, V., Wang, L., Schwaiger, S., Heiss, E.H., Rollinger, J.M., Schuster, D., Breuss, J.M., Bochkov, V., Mihovilovic, M.D., Kopp, B., Bauer, R., Dirsch, V.M. \& Stuppner, H. 2015. Discovery and resupply of pharmacologically active plant-derived natural products: A review. Biotechnol. Adv. 33: 1582-1614.

Chemler, J.A. \& Koffas, M.A. 2008. Metabolic engineering for plant natural product biosynthesis in microbes. Curr. Opin. Biotechnol. 19: 597-605.

Christensen, A.B., Gregersen, P.L., Schroder, J. \& Collinge, D.B. 1998. A chalcone synthase with an unusual substrate preference is expressed in barley leaves in response to UV light and pathogen attack. Plant Mol. Biol. 37: 849-857.

Falcone Ferreyra, M.L., Rius, S.P. \& Casati, P. 2012. Flavonoids: biosynthesis, biological functions, and biotechnological applications. Front. Plant Sci. 3: 1-15.

Fowler, Z.L., Gikandi, W.W. \& Koffas, M.A. 2009. Increased malonyl coenzyme A biosynthesis by tuning the Escherichia coli metabolic network and its application to flavanone production. Appl. Environ. Microbiol. 75: 5831-5839.

Fowler, Z.L. \& Koffas, M.A. 2009. Biosynthesis and biotechnological production of flavanones: current state and perspectives. Appl. Microbiol. Biotechnol. 83: 799-808.

Ganesan, V., Li, Z., Wang, X. \& Zhang, H. 2017. Heterologous biosynthesis of natural product naringenin by co-culture engineering. Synth. Syst. Biotechnol. 2: 236-242.

Gietz, R.D. \& Schiestl, R.H. 2007. High-efficiency yeast transformation using the LiAc/SS carrier DNA/PEG method. Nat. Protoc. 2: 31-34.

Hermenean, A., Ardelean, A., Stan, M., Herman, H., Mihali, C.V., Costache, M. \& Dinischiotu, A. 2013. Protective effects of naringenin on carbon tetrachloride-induced acute nephrotoxicity in mouse kidney. Chem. Biol. Interact. 205: 138-147.

Jiang, H., Wood, K.V. \& Morgan, J.A. 2005. Metabolic engineering of the phenylpropanoid pathway in Saccharomyces cerevisiae. Appl. Environ. Microbiol. 71: 2962-2969.

Jones, J.A., Toparlak, Ö.D. \& Koffas, M.A.G. 2015. Metabolic pathway balancing and its role in the production of biofuels and chemicals. Curr. Opin. Biotechnol. 33: 52-59.

Koopman, F., Beekwilder, J., Crimi, B., van Houwelingen, A., Hall, R.D., Bosch, D., van Maris, A.J., Pronk, J.T. \& Daran, J.M. 2012. De novo production of the flavonoid naringenin in engineered Saccharomyces cerevisiae. Microb. Cell Fact. 11: 155-170.
فرمنتيشن و افزودن بازدارنده سرلانين به محيط كشت مىتواند سبب

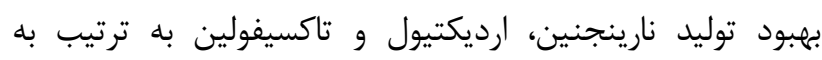

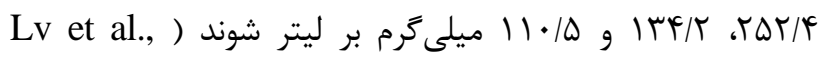
2019b). درحالى كه كاهش هزينه توليد تركيبات فلاونوئيدى از طريق كاهش مصرف كلوكز در محيط كشت و عدم افزودن تركيبات

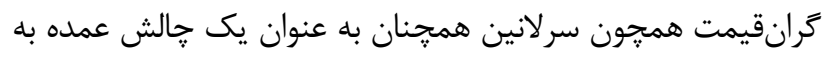
شمار مىرود كه محققان تلاش دارند از طريق توليد مسيرهاى بيوسنتز هترولوگ تكراريذير و كاهش سرمايهزَارىهاى اوليه اين موانع را رفع كنند (Zhu \& Jackson, 2015). نتايج حاصل از اين بررسى نشان داد كه درك كافى از مسير

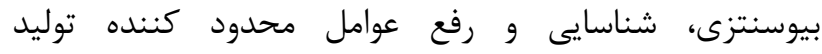

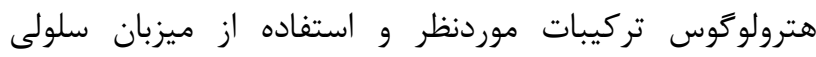
قدرتمند مىتواند سبب بهينهسازى توليد تركيبات ارزشمند دارويى به روش بسيار ايمن در مقياس وسيع و با هزينه كمتر نسبت به استخراج از مواد كياهى و يا سنتز شيميايى شوند.

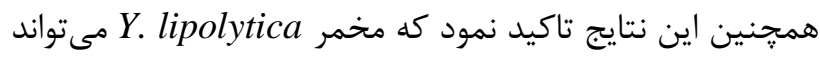
با بهرهذيرى از آنزيمها و سوبستراهاى ذاتى خود منجر به به بهبود سنتز تر كيبات خارجى شود.

$$
\text { سياسگَزارى }
$$

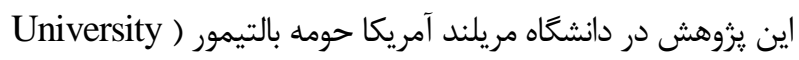
(of Maryland, Baltimore County, USA انجام اين يروزه توسط دانشخاه مريلند، بنياد ملى علوم ( National (Science Foundation; NSF شد. بههمينمنظور از يرسنل محترم اين مؤسسهها جهت همكارىهاى بىدريغ و حمايت مالى قدردانى مىشود. 
Leonard, E., Ajikumar, P., Thayer, K., Xiao, W., Mo, J., Tidor, B., Stephanopoulos, G. \& Prather, K. 2010. Combining metabolic and protein engineering of a terpenoid biosynthetic pathway for overproduction and selectivity control. Proc. Natl. Acad. Sci. USA 107: 13654-13659.

Lian, J., Mishra, S. \& Zhao, H. 2018. Recent advances in metabolic engineering of Saccharomyces cerevisiae: New tools and their applications. Metab. Eng. 50: 85-108.

Lv, Y., Edwards, H., Zhou, J. \& Xu, P. 2019a. Combining 26s rDNA and the Cre-loxP system for iterative gene integration and efficient marker curation in Yarrowia lipolytica. ACS Synth. Biol. 8: 568-576.

Lv, Y., Marsafari, M., Koffas, M., Zhou, J. and Xu, P. 2019b. Optimizing oleaginous yeast cell factories for flavonoids and hydroxylated flavonoids biosynthesis. ACS Synth. Biol. 8: 2514-2523.

Mahomoodally, M.F., Gurib-Fakim, A. \& Subratty, A.H. 2005. Antimicrobial activities and phytochemical profiles of endemic medicinal plants of mauritius. Pharm. Biol. 43: 237-242.

Panche, A.N., Diwan, A.D. \& Chandra, S.R. 2016. Flavonoids: an overview. J. Nutr. Sci. 5: 1-15.

Pandy, A.K. 2007. Anti-staphylococcal activity of a pantropical aggressive and obnoxious weed Parthenium histerophorus: An in vitro study. Natl Acad Sci Lett. 30: 383-386.

Ribeiro, I.A., Rocha, J., Sepodes, B., Mota-Filipe, H. \& Ribeiro, M.H. 2008. Effect of naringin enzymatic hydrolysis towards naringenin on the anti-inflammatory activity of both compounds. J. Mol. Catal. B-Enzym. 5253: $13-18$.

Santos, C.N.S., Koffas, M. \& Stephanopoulos, G. 2011. Optimization of a heterologous pathway for the production of flavonoids from glucose. Metab. Eng. 13: 392-400.

Stafford, H.A., Runeckles, V.C. \& Conn, E.E. 1974. Possible Multienzyme Complexes Regulating the Formation of C6-C3 Phenolic Compounds and Lignins in Higher Plants. Recent Adv. Phytochem. 8: 53-79.

Trantas, E.A., Koffas, M.A., Xu, P. \& Ververidis, F. 2015. When plants produce not enough or at all: metabolic engineering of flavonoids in microbial hosts. Front. Plant Sci. 6: 7-23.

van Tunen, A.J., Koes, R.E., Spelt, C.E., van der Krol, A.R., Stuitje, A.R. \& Mol, J.N. 1988. Cloning of the two chalcone flavanone isomerase genes from Petunia hybrida: coordinate, light-regulated and differential expression of flavonoid genes. Embo. J. 7: 1257-1263.

Wang, Y., Chen, S. \& Yu, O. 2011. Metabolic engineering of flavonoids in plants and microorganisms. Appl. Microbiol. Biotechnol. 91: 949-956.

Winkel, B.S. 2004. Metabolic channeling in plants. Annu Rev Plant Biol. 55: 85-107.
Winkel-Shirley, B. 2001. Flavonoid biosynthesis. A colorful model for genetics, biochemistry, cell biology, and biotechnology. Plant Physiol. 126: 485-493.

Winkel-Shirley, B. 2002. Biosynthesis of flavonoids and effects of stress. Curr. Opin. Plant Biol. 5: 218-223.

Wong, L., Engel, J., Jin, E., Holdridge, B. \& Xu, P. 2017. YaliBricks, a versatile genetic toolkit for streamlined and rapid pathway engineering in Yarrowia lipolytica. Metab. Eng. Commun. 5: 68-77.

Wu, J., Du, G., Zhou, J. \& Chen, J. 2013. Metabolic engineering of Escherichia coli for (2S)-pinocembrin production from glucose by a modular metabolic strategy. Metab. Eng. 16: 48-55.

Wu, J., Zhou, T., Du, G., Zhou, J. \& Chen, J. 2014. Modular optimization of heterologous pathways for de novo synthesis of (2S)-naringenin in Escherichia coli. PLOS ONE 9: e101492.

Xu, C., Chen, J., Zhang, J., Hu, X., Zhou, X., Lu, Z. \& Jiang, H. 2013a. Naringenin inhibits angiotensin IIinduced vascular smooth muscle cells proliferation and migration and decreases neointimal hyperplasia in balloon injured rat carotid arteries through suppressing oxidative stress. Biol. Pharm. Bull. 36: 1549-1555.

Xu, P., Bhan, N. \& Koffas, M.A.G. 2013b. Engineering plant metabolism into microbes: from systems biology to synthetic biology. Curr. Opin. Biotechnol. 24: 291-299.

Xu, P., Qiao, K.J., Ahn, W.S. \& Stephanopoulos, G. 2016. Engineering Yarrowia lipolytica as a platform for synthesis of drop-in transportation fuels and oleochemicals. Proc. Natl. Acad. Sci. USA 113: 1084810853.

Zelcbuch, L., Antonovsky, N., Bar-Even, A., Levin-Karp, A., Barenholz, U., Dayagi, M., Liebermeister, W., Flamholz, A., Noor, E., Amram, S., Brandis, A., Bareia, T., Yofe, I., Jubran, H. \& Milo, R. 2013. Spanning high-dimensional expression space using ribosome-binding site combinatorics. Nucleic Acids Res. 41: e98-e106.

Zha, W., Rubin-Pitel, S.B., Shao, Z. \& Zhao, H. 2009. Improving cellular malonyl-CoA level in Escherichia coli via metabolic engineering. Metab Eng. 11: 192-198.

Zhang, H. and Stephanopoulos, G. 2013. Engineering E. coli for caffeic acid biosynthesis from renewable sugars. Appl. Microbiol. Biotechnol. 97: 3333-3341.

Zhang, W., Liu, H., Li, X., Liu, D., Dong, X.-T., Li, F.-F., Wang, E.-X., Li, B.-Z. \& Yuan, Y.-J. 2017. Production of naringenin from D-xylose with co-culture of $E$. coli and S. cerevisiae. Eng. Life. Sci. 17: 1021-1029.

Zhu, Q. \& Jackson, E.N. 2015. Metabolic engineering of Yarrowia lipolytica for industrial applications. Curr. Opin. Biotechnol. 36: 65-72.

Zhu, S., Wu, J., Du, G., Zhou, J. \& Chen, J. 2014. Efficient synthesis of eriodictyol from L-tyrosine in Escherichia coli. Appl. Environ. Microbiol. 80: 3072-3080.

How to cite this article:

Marsafari, M., Samizadeh, H., Rabiei1, B., Ashraf Mehrabi, A., Lv, Y. \& Xu, P. 2020. The optimization of Naringenin biosynthesis pathway using Yarrowia lipolytica cell culture. Nova Biologica Reperta 7: 133-144. (In Persian).

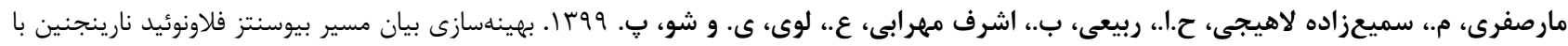

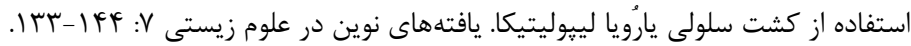

